Article

\title{
Web-Based Tool for the Development of Intensity Duration Frequency Curves under Changing Climate at Gauged and Ungauged Locations
}

\author{
Andre Schardong ${ }^{1, *}$, Slobodan P. Simonovic ${ }^{1} \mathbb{D}$, Abhishek Gaur ${ }^{2}$ and Dan Sandink ${ }^{3}$ \\ 1 Faculty of Engineering, Western University, London, ON N6G 1G8, Canada; simonovic@uwo.ca \\ 2 National Research Council Canada, Ottawa, ON K1A 0R6, Canada; abhishek.gaur@nrc-cnrc.gc.ca \\ 3 Institute for Catastrophic Loss Reduction, Toronto, ON M5C 2R9, Canada; dsandink@iclr.org \\ * Correspondence: aschardo@uwo.ca; Tel.: +1-226-272-0040
}

Received: 29 March 2020; Accepted: 24 April 2020; Published: 27 April 2020

check for updates

\begin{abstract}
Rainfall Intensity-Duration-Frequency (IDF) curves are among the most essential datasets used in water resources management across the globe. Traditionally, they are derived from observations of historical rainfall, under the assumption of stationarity. Change of climatic conditions makes use of historical data for development of IDFs for the future unreliable, and in some cases, may lead to underestimated infrastructure designs. The IDF_CC tool is designed to assist water professionals and engineers in producing IDF estimates under changing climatic conditions. The latest version of the tool (Version 4) provides updated IDF curve estimates for gauged locations (rainfall monitoring stations) and ungauged sites using a new gridded dataset of IDF curves for the land mass of Canada. The tool has been developed using web-based technologies and takes the form of a decision support system (DSS). The main modifications and improvements between version 1 and the latest version of the IDF_CC tool include: (i) introduction of the Generalized Extreme value (GEV) distribution; (ii) updated equidistant matching algorithm (QM); (iii) gridded IDF curves dataset for ungauged location and (iv) updated Climate Models.
\end{abstract}

Keywords: Intensity-Duration-Frequency Curve; climate change; decision support system; Canada

\section{Introduction}

Rainfall Intensity-Duration-Frequency (IDF) curves describe the relationship between rainfall intensity, rainfall duration, and the probability of exceedance given by the return period (frequency) and are used for many water management applications, including the design of major and minor stormwater management systems, sanitary sewers, detention ponds, culverts, bridges, dams, pumping stations, and roads, among others [1]. In Canada, we are witnessing a growing demand for robust methods and tools to assist rapid evaluation of the future extreme rainfall events and their impact on IDF curves. According to [1], the increase in the demand for rainfall IDF information can be summarized as follows: (i) as the spatial heterogeneity of extreme rainfall patterns becomes better understood and documented, a stronger case is made for the value of "locally relevant" IDF information; (ii) as urban areas expand and evolve, watersheds are generally becoming less permeable to rainfall and consequently, experiencing increased runoff, and many existing water infrastructures are increasingly failing to perform at the services levels for which they were designed. Understanding the full magnitude of the deficit the systems are subject to requires information on the maximum inputs (extreme rainfall events) with which drainage works must contend; and (iii) climate change will likely result in an increase in the intensity and frequency of extreme precipitation events in most regions in the future [2].

One of the climate change impacts is intensification of the global hydrologic cycle, causing increased intensity of wet and dry extremes and resulting floods and droughts [3]. Many studies 
have suggested that climate change will have considerable impacts on extreme rainfall and associated management of water infrastructure [4-10]. Efforts have been made to better understand and improve the reliability of the projected future precipitation events [11] with the adjusted forcing scenarios defined for CMIP5 (Coupled Model Intercomparison Project Phase 5). In particular, the PDRMIP (Precipitation Driver and Response Model Intercomparison Project) [12] is focusing on evaluating the climate change drivers of precipitation with changes over land versus ocean and key regions of the globe. It is expected that the PDRMIP will contribute to the adjustment of forcing scenarios for the CMPI6 (Coupled Model Intercomparison Project Phase 6), currently in full swing [12,13]. There has been a notable increase in damages associated with extreme rainfall events in urban municipalities and some examples of the impacts of extreme rainfall events on large urban centers in Canada and the economic losses are presented in $[14,15]$. Lack of readily and easily accessible data, information to assess adaptation options, and availability of technical resources to implement adaptation options have been identified as barriers to climate change adaptation [16]. In addition, much of the work on the impacts of climate change on design standards has been conducted in the academia with limited availability of research results to practitioners. Political factors may also inhibit application of design standards that reflect increasing intensity and frequency of extreme events. Further, there exists a level of uncertainty associated with future climate projections, in particular with the uncertainty surrounding the future greenhouse gas concentration scenarios, also known as Representative Concentration pathways [11-13,17] (RCPs), creating difficulty in application of results. The issue is further aggravated by the presence of various uncertainties associated with the use of several distinct GCMs (Global Climate Models) given the limited capacity for projecting, with high accuracy, longer term precipitation events and large spatial scales (usually larger than the size of most watersheds) and distinct potential downscaling techniques.

Because of changing conditions, IDF values will optimally need to be updated more frequently than in the past, and climate change scenarios are required to inform IDF calculations. The main assumption in the process of developing IDF curves is that historical series are stationary and, therefore, can be used to represent future extreme conditions. This assumption is not valid under rapidly changing conditions, and therefore, IDF curves that rely only on historical observations will misrepresent future conditions $[18,19]$. In the presence of climate change, the statistical characteristics of the historical observed rainfall events will be different for future conditions. Limited information is available on how to bring climate change into the IDF calculations [20-25] and even less on how to implement updated IDF curves in practice [26]. Authors such as [27,28] have presented decision support systems to assist in the calculation of IDF curves, using GIS tools and Microsoft Excel, respectively.

The rainfall IDF_CC tool is designed to address this gap. The authors and supporting agencies strongly believe that a publicly available, computerized tool for updating IDF relationships under changing climate would aid in the selection of effective climate change adaptation options at the local level, advancing the decision-making capabilities of municipalities and watershed management authorities.

The initial version of the IDF_CC tool, version 1, was publicly released in 2015 [4,26]. A second version was made public in August 2017, and since then, new features have been introduced into the current version of the tool, which are described in this paper. The significant improvements of the last version of the tool include: (i) use of the General Extreme Value (GEV) distribution, (ii) a new quantile matching (QM) algorithm for updating IDFs using the GEV distribution; (iii) addition of a new module for developing IDF curves for ungauged locations across Canada and a methodology for updating them under climate change and (iv) new and updated climate models used for the IDF projections.

The manuscript is organized as follows: Section 2 describes the methodology implemented for the calculation of IDF curves under climate change; the description of the IDF_CC implementation follows in Sections 3 and 4 provides a detailed guide for IDF_CC tool use the discussion of the results and uncertainty - and provides some conclusions, in Section 5, based on the up-to-date public use of the tool. 


\section{Methodology}

This section presents the methodology development and use with the IDF_CC tool version 4 and changes made to the tool since the publication of version 1 . We briefly describe version 1 of the tool, and then the changes introduced to versions 2, 3 and 4. These changes include: (1) use of the GEV distribution; (2) additional climate data with new climate projections; and (3) new gridded IDF curves dataset. With use of the GEV distribution and a new dataset for ungauged IDF curves (gridded dataset), the algorithms for updating IDF curves under climate change had to be modified and adapted from the original version 1. These methods are described in Sections 2.3 and 2.4.

\subsection{IDF_CC Tool}

The IDF_CC tool version 1 was made public in March 2015 and has since been used by a large number of practitioners, consultants, and municipal engineers [26]. IDF_CC tool version 1 used an original equidistant quantile-matching (EQM) downscaling method for updating IDF curves $[4,20]$. The goal was to mimic changes between the projected time period and the baseline period from climate models. The methodology used the Gumbel distribution fitted to the annual maximum precipitation (AMP) series of the observed data and the series extracted from the GCMs using the method of moments to estimate the parameters. The quantile-mapping functions are directly applied to annual maximum precipitation (AMP) to establish statistical relationships between the AMPs of GCM generated precipitation data and sub-daily observed (historical) data rather than using complete daily precipitation records. Details of the implementation and use of the tool are detailed in [4] and [26]. Version 1 of the tool has been used to estimate changes in IDF curves for Canada and produce interpolated gridded maps [29]. Another study [30] details an analysis comparing the IDF_CC future IDF projections to the theoretical Clausius-Clapeyron scaling that estimates a constant rate of increase in short-duration precipitation, based on temperature increase.

Since version 1 was released, the IDF tool was improved and several new features were added and are described in more detail in the following sections:

- Implementation of the General Extreme Value (GEV) distribution with the L-moments methods (described in Section 2.2).

- Introduction of the module for development of IDF curves for ungauged locations (described in Section 2.3).

- Update of the database with the stations from the Environment and Climate Change Canada (ECCC) IDF engineering dataset [31].

- Update of the climate models data base with second version of bias corrected climate models from the Pacific Climate Impacts Consortium [32].

\subsection{Statistical Distributions}

This section describes the statistical distributions and the estimation of the parameters used in the IDF_CC tool.

\subsubsection{Gumbel Distributions}

The Gumbel distribution, usually denoted in its general form by $G(x ; \mu, \sigma)$ with $\mu$ location and $\sigma$, the scale parameter, is used as the standard distribution by ECCC for all precipitation frequency analyses in Canada. The annual extremes quantiles can be expressed as follows:

$$
Q_{t}=\mu+K_{T} \sigma
$$


where $Q_{t}$ is the exceedance value, $\mu$ and $\sigma$ are the mean and standard deviation (parameters of the distribution) of the annual extreme series and $K_{T}$ the frequency factor, that can be calculated as follows:

$$
K_{T}=\frac{\sqrt{6}}{\pi}\left[0.5772+\ln \left[\ln \left(\frac{T}{T-1}\right)\right]\right]
$$

where $T$ is return period in years.

For the parameter estimation of the Gumbel distribution, ECCC uses and recommends the method of moments technique [33] as it is simple and yields consistent estimators. In the case of the Gumbel distribution, the parameters $\mu$ and $\sigma$ are estimated by moments methods from data series.

\subsubsection{GEV Distribution}

The General Extreme Value (GEV) distribution, usually denoted in its general form by GEV(x; $\mu, \alpha, k)$ with $\mu$ the location, $\alpha$ the scale and $k$ the shape parameter of the distribution, is a family of continuous probability distributions that combines the three asymptotic extreme value distributions into one: Gumbel (EV1), Fréchet (EV2) and Weibull (EV3) types. GEV uses three parameters: location, scale and shape. The shape parameter is derived from skewness, as it represents where most of the data lies, which creates the tail(s) of the distribution. A value of shape parameter $k=0$ indicates an EV1 distribution. A value of $k>0$, indicates EV2 (Fréchet), and $k<0$ indicates the EV3 distribution (Weibull). The Fréchet type has a longer upper tail than the Gumbel distribution and the Weibull type has a shorter tail [34-37]. For this reason, the GEV distribution can potentially provide a better fit to the precipitation data than the 2-parameter Gumbel distribution [35,38-41].

The GEV cumulative distribution function $F(x)$ is given by (3) for $k \neq 0$ and (4) for $k=0$ (EV1).

$$
\begin{gathered}
F(x)=\exp \left\{-\left[1-\frac{k}{\alpha}(x-\mu)\right]^{1 / k}\right\} \text { for } k \neq 0 \\
F(x)=\exp \left\{-\exp \left[-\frac{1}{\alpha}(x-\mu)\right]\right\} \text { for } k=0
\end{gathered}
$$

with $\mu$ the location, $\alpha$ the scale and $k$ the shape parameter of the distribution, with $\mu, \alpha$ and $k \in \mathbb{R}$ and $\alpha \geq 0$.

The inverse distribution function or quantile function is given by (5) for $k \neq 0$ and (6 for $k=0$, and the other parameters as described above.

$$
\begin{gathered}
Q(x)=\mu+\alpha\left\{1-(-\ln F)^{k}\right\} / k \text { for } k \neq 0 \\
Q(x)=\mu-\alpha\left\{-\exp \left[-\frac{1}{\alpha}(F-\mu)\right]\right\} \text { for } k=0
\end{gathered}
$$

Parameter estimation with the L-moments method

The L-moments $[28,42]$ and maximum-likelihood methods are commonly used to estimate the parameters of the GEV distribution and fit to annual maxima series. L-moments are a modification of the probability-weighted moments (PWMs), as they use the PWMs to calculate parameters that are easier to interpret. The PWMs can be used in the calculation of parameters for statistical distributions $[34,36]$. L-moments is a robust alternative to moments of the distributions and is a linear combination of the order statistics of the annual maximum rainfall amounts $[34,35,43]$. The PWMs are estimated by $((7)$ to $(9))$ :

$$
\begin{gathered}
b_{0}=n^{-1} \sum_{j=1}^{n} x_{j} \\
b_{1}=n^{-1} \sum_{j=2}^{n} \frac{j-1}{n-1} x_{j}
\end{gathered}
$$




$$
b_{2}=n^{-1} \sum_{j=3}^{n} \frac{(j-1)(j-2)}{(n-1)(n-2)} x_{j}
$$

where $x_{j}$ is the ordered sample of annual maximum series (AMP) and $b_{i}$ are the first PWMs. The sample L-moments can then obtained as (Equations (10)-(12)):

$$
\begin{gathered}
\ell_{1}=b_{0} \\
\ell_{2}=2 b_{1}-b_{0} \\
\ell_{3}=6 b_{2}-6 b_{1}+b_{0}
\end{gathered}
$$

The GEV parameters: location $(\mu)$, scale $(\alpha)$ and shape $(k)$ are defined ([34]) as (Equations (13)-(15)):

$$
\text { where: } \begin{gathered}
\quad k=7.8590 c+2.9554 c^{2} \\
c=\frac{2}{3+\ell_{3} / \ell_{2}}-\frac{\ln (2)}{\ln (3)} \\
\alpha=\frac{\ell_{2} k}{\left(1-2^{-k}\right) \cdot \Gamma(1+k)} \\
\mu=\ell_{1}-\alpha \frac{1-\Gamma(1+k)}{k}
\end{gathered}
$$

where $\Gamma\left(\right.$.) is the gamma function, $\ell_{1}, \ell_{2}$ and $\ell_{3}$ are the three first L-moments, $\mu$ is the location, $\alpha$ is the scale and $k$ is the shape parameter of the GEV distribution.

\subsection{IDF Curves for Ungauged Locations}

One important addition that has been made in the latest version of the IDF_CC tool, and described in this manuscript, is gridded IDF estimates across Canada. The intention in including this dataset is to allow development of IDF curves at ungauged locations across Canada by users of the tool. The methodology involves making preliminary estimates of IDF curves from atmospheric variables $(\mathrm{AVs})$ that shape precipitation extremes in different parts of Canada, and then performing a bias-correction function to correct for spatial errors. A summary of the methodology is provided in the following five steps. For a detailed description of the methodology and specific analysis of the created ungauged dataset, the reader is directed to [44].

\section{Step 1: Preparation of predictors}

Daily time-series of AVs are extracted for all grids located within Canada for the period 1979-2013 from North American Regional Reanalysis (NARR) [45] and ERA-Interim [46] databases. Extracted time-series are used to calculate annual mean and maximum AV values to obtain an array of 31 predictors at all reanalysis grid-points. These are used later in step 4 for the prediction of preliminary IDF estimates. The calculated predictor variables are bi-linearly interpolated to obtain predictor values at all precipitation gauging station locations. These are used in steps 2 and 3 to identify relevant AVs and to calibrate machine learning algorithms at each precipitation gauging station location.

\section{Step 2: Identification of relevant AVs at precipitation gauging station locations}

The most relevant $\mathrm{AVs}$ out of the 31 potential $\mathrm{AVs}$ are identified at precipitation gauging stations with at least 10 years of observational data. Individual sets of relevant $\mathrm{AVs}$ are obtained for precipitation extremes of different durations. Since annual mean precipitation (P-mean) has been identified as an important predictor when modelling precipitation extremes [47,48], it is considered as a 'reference' predictor in this study. This means that $P$-mean is considered as one of the relevant predictors at all precipitation gauging stations.

The relevance of other AVs toward shaping AMP magnitudes is evaluated at each precipitation gauging station by performing a chi-squared test and correlation analysis. Chi-squared tests are 
performed to compare two nested linear regression models of observed AMP magnitudes: (1) model with only a 'reference' predictor, and (2) model with a 'reference' and a 'test' predictor. It is ascertained whether the inclusion of the 'test' predictor variable leads to a statistically significant improvement (at $p=0.05$ ) in the definition of model 1 or not. AVs resulting in a statistically significant improvement in regression model definition are also identified as relevant predictor variables. In addition, correlations between AMP and different AVs and extreme precipitation magnitudes are calculated and highly correlated AVs are also considered for modelling AMP magnitudes.

Step 3: Calibration of machine learning (ML) models at precipitation gauging stations

Next, ML models describing AMP magnitudes as a function of identified relevant AVs are calibrated at each precipitation gauging station, for each of the sub-daily durations. To minimize the risk of obtaining unstable regression relationships at stations with short data lengths, observational and AV data from neighboring stations falling within a pooling extent are pooled when forming a relationship between AMP and relevant AVs. In this study, two pooling extents encompassing 10 and 25 closest stations surrounding the gauging station of interest are considered for analysis. One machine learning algorithm, SVM (support vector machines) [49], is used to define the relationship between predictant and predictor variables. The kernlab package [50] in the $\mathrm{R}$ programming language. The Sequential Minimal Optimization procedure [51] is chosen as the optimization procedure for estimating SVM regression parameters. The results produced by this algorithm in $\mathrm{R}$ are then incorporated in the IDF_CC tool, as described in Section 3.1.

\section{Step 4: Prediction of preliminary IDF estimates at reanalysis grids}

Prediction of preliminary IDF estimates for a particular reanalysis grid is made by using a calibrated ML model from the nearest precipitation gauging station and time-series of predictors associated with the reanalysis grid as calculated in step 1 . This process is repeated for all reanalysis grids and precipitation durations to obtain gridded AMP estimates across Canada. Obtained AMP estimates are fitted to a Generalized Extreme Value (GEV) distribution and precipitation intensities corresponding to 2-, 5-, 10-, 25-, 50-, and 100-year return periods are estimated.

\section{Step 5: Correction of spatial errors}

In the final step, the estimated preliminary IDF magnitudes are bilinearly interpolated at precipitation gauging station locations and used in conjunction with observation-based IDF magnitudes to obtain correction factors at each precipitation gauging station location. Different sets of correction factors are calculated for IDFs of different durations and return periods. Correction factor $C_{d, f, s}$ obtained at a gauging station $s$, for a precipitation event of duration $d$, and frequency $f$ is calculated as:

$$
C_{d, f, s}=\frac{I D F_{o b s, d, f, s}}{I D F_{m o d, d, f, s}}
$$

where, subscripts obs and mod denote observed and modelled data, respectively. Correction factors calculated at each precipitation gauging station are bilinearly interpolated to obtain gridded correction factors for all reanalysis grids located within Canada. Correction factors obtained for reanalysis grids are multiplied with preliminary IDF estimates to obtain final gridded IDF estimates. The spatial distribution of the correction factors indicates a higher accuracy of preliminary estimates in both eastern and western coastal regions of Canada, south-western Ontario, and northern Quebec regions. Relatively lower accuracy in preliminary estimates is obtained for northern Ontario, prairies and the majority of the northern regions of Canada.

\subsection{IDF Curves under Changing Climate}

The main assumption in the process of developing IDF curves is that the historical series are stationary and, therefore, can be used to represent future extreme conditions. This assumption is not valid under rapidly changing conditions, and therefore, IDF curves that rely only on historical observations will misrepresent future conditions [52,53]. Global Climate Models (GCMs) are one of the best ways to explicitly address changing climate conditions for future periods (i.e., non-stationary 
conditions). GCMs simulate atmospheric patterns on larger spatial grid scales (usually greater than $100 \mathrm{~km}$ ) and are, therefore, unable to represent the regional scale dynamics accurately. In contrast, regional climate models (RCMs) are developed to incorporate the local-scale effects and use smaller grid scales, usually 10 to $50 \mathrm{~km}$ or even less. The major shortcoming of RCMs is the computational intensity required to generate realizations for various atmospheric forcings.

Both GCMs and RCMs have larger spatial scales than the size of most watersheds, which is the relevant scale for IDF curves. Downscaling is one of the techniques to link GCM/RCM grid scales and local study areas for the development of IDF curves under changing climate conditions. Downscaling approaches can be broadly classified as either dynamic or statistical. The dynamic downscaling procedure is based on limited area models or uses higher resolution GCM/RCM models to simulate local conditions, whereas statistical downscaling procedures are based on transfer functions which relate GCM outputs with the local study areas; that is, a mathematical relationship is developed between GCM outputs and historically observed data for the time period of observations. Statistical downscaling procedures are used more widely than dynamic models because of their lower computational requirements and availability of GCM outputs for a wider range of emission scenarios.

The IDF_CC tool adopts a modified version of the equidistant quantile-matching (EQM) method [20] for temporal downscaling of precipitation data which can capture the distribution of changes between the projected time period and the baseline. Future projections are incorporated by using the concept of quantile delta mapping [54-56], also known as scaling. For spatial downscaling, the tool utilizes data from GCMs produced for Coupled Model Intercomparison Project Phase 5 (CMIP5) [50] and statistically downscaled daily Canada-wide climate scenarios, at a gridded resolution of 300 arc-seconds ( 0.0833 degrees, or roughly $10 \mathrm{~km}$ ) for the simulated period of 1950-2100 [32]. Spatially and temporally downscaled information is used for updating IDF curves.

\subsubsection{Equidistant Quantile Matching Method with GEV}

The IDF_CC tool uses an equidistant quantile matching (EQM) method to update IDF curves under changing climate conditions by temporally downscaling precipitation data to explicitly capture the changes in the GCM data between the baseline period and a future period. The flow chart of the EQM methodology is shown in Figure 1.

The following section presents the EQM method for updating the IDF curves that is employed by the IDF_CC tool. The following notation is used in the descriptions of the EQM steps: $x$, stands for the annual maximum precipitation, $j$ is the subscript for 5, 10, $15 \mathrm{~min}, 1,2,6,12,24 \mathrm{~h}$ sub-daily durations, $o$ the observed historical series, $h$ for historical simulation period (base-line for model data), $m$ for model (downscaled GCMs), $f$ the sub/superscript for the future projected series, $F$ the CDF of the fitted probability GEV distribution and $F^{-1}$ the inverse CDF. The steps involved in the algorithm are as follows:

1. Extract sub-daily maximums $x_{j, o, h}$ from the observed data at a given location (i.e., maximums of 5, 10, 15 min, 1, 2, 6, 12, 24 h precipitation data).

2. Extract daily maximums for the historical baseline period from the selected GCMs, $x_{m, h}$.

3. Fit the GEV probability distribution to maxima series extracted in (i) for each sub-daily duration, $F_{j, o, h}$, and for the GCM series from step (ii), $F_{m, h}$.

4. Based on sampling technique proposed by [22], generate random numbers for non-exceedance probability in the $[0,1]$ range. The quantiles extracted from the GEV fitted to each pair $F_{j, o, h}$ and $F_{m, h}$ are equated to establish a statistical relationship in the following form:

$$
\hat{x}_{j, o, h}=\frac{a_{j}+x_{m, h}}{b_{j}+c_{j} x_{m, h}}+\frac{d_{j}}{x_{m, h}}
$$


where $\hat{x}_{j, o, h}$ corresponds to the AMP quantiles at the station scale and $a_{j}, b_{j}, c_{j}$ and $d_{j}$, are the adjusted coefficients of the equation for each sub-daily duration $j$. A Differential Evolution (DE) optimization algorithm is used to fit the coefficients $a_{j}, b_{j}, c_{j}$ and $d_{j}$.

5. Extract daily maximums from the RCP Scenarios used in the IDF_CC tool (i.e., RCP 2.6, RCP 4.5, RCP 8.5) for the selected GCM model, $x_{m, f}$.

6. Fit the GEV probability distribution to the daily maximums from the GCM model for each of the future scenarios $F_{m, f}$.

7. For each projected future precipitation series $x_{m, f}$, calculate the non-exceedance probability $\tau_{m, f}$ from the fitted GEV $F_{m, f}$. Find the corresponding quantile $\left(\hat{x}_{m, h}\right)$ at the GCM historical baseline by entering the value of $\tau_{m, f}$ in the inverse CDF $F_{m, h}^{-1}$. This is a scaling step introduced to incorporate the future projections in the updated IDF and uses the concepts of quantile delta mapping $[54,56]$. The relative change $\Delta_{m}$, is calculated using Equation (20):

$$
\begin{gathered}
\tau_{m, f}=F_{m, f}\left(x_{m, f}\right) \\
\hat{x}_{m, h}=F_{m, h}^{-1}\left(\tau_{m, f}\right) \\
\Delta_{m}=\frac{x_{m, f}}{\hat{x}_{m, h}}
\end{gathered}
$$

8. To generate the projected future maximum sub-daily series at the station scale $\left(x_{j, 0, h}^{f}\right)$, use (17) by replacing $x_{m, h}$ to $\hat{x}_{m, h}$ and multiplying by the relative change $\Delta_{m}$ from Equation (20).

$$
x_{j, o, h}^{f}=\Delta_{m} \cdot \hat{x}_{j, o, h}
$$

9. Generate IDF curves for the future sub-daily data and compare the same with the historically observed IDF curves to observe the change in intensities.

\subsubsection{Spatial Interpolation of GCM Data}

GCM spatial grid size scales are too coarse for application in updating IDF curves, and usually range above $1.5^{\circ} \times 1.5^{\circ}$. Therefore, GCM data has to be spatially interpolated for station coordinates for use in downscaling. The inverse square distance weighting method is applied in the IDF_CC tool. The nearest four GCM grid points to the station are used by weighting the precipitation value by the distance between the station and the GCM grid points. In this way, the GCM grid points that are closer to the station are weighted more than the grid points farther away. The mathematical expression for the inverse square distance weighting method is given as follows:

$$
w_{i}=\frac{\frac{1}{d_{i}^{2}}}{\sum_{i=1}^{k} \frac{1}{d_{i}^{2}}}
$$

where $d_{i}$ is the distance between the $i$ th GCM grid point and the station, and $k$ is the number of nearest grid points (equal to 4 in the IDF_CC tool). 


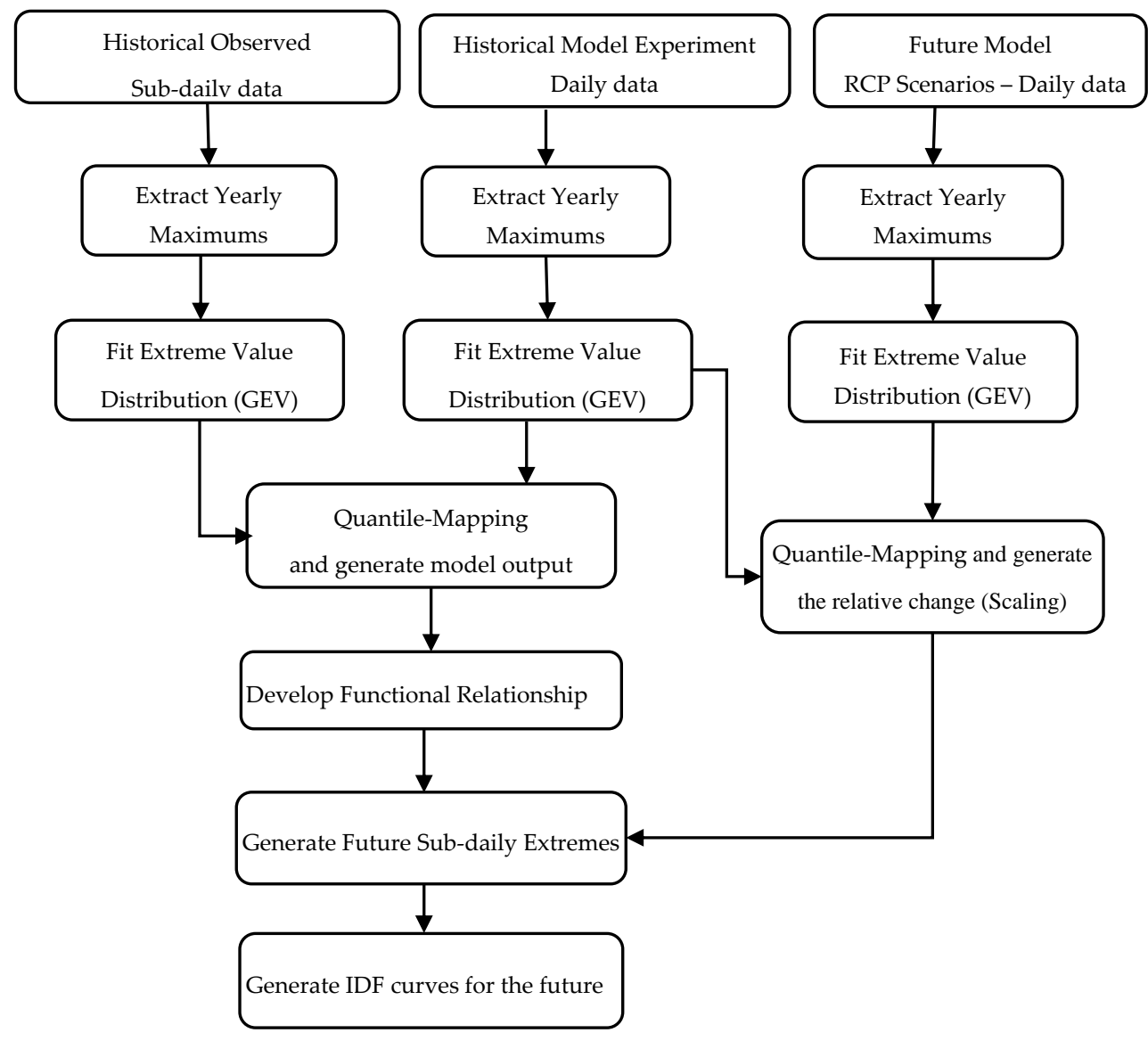

Figure 1. Equidistance Quantile-Matching method for generating future Intensity-Duration-Frequency (IDF) curves under climate change.

\subsection{Updating IDFs for Ungauged Locations}

The updating procedure for ungauged locations adopts a modified version of the equidistant quantile matching (EQM) discussed in [20]. Changes in future conditions due to climate change are captured from GCMs by evaluating the magnitude and sign of change, comparing the model's baseline and future periods for each RCP, and then applied to the IDF estimates from the gridded data. The flow chart of the modified EQM methodology is shown in Figure 2.

The following discussion presents the modified EQM method for updating the IDF curves for gridded data that is employed by the current version of the IDF_CC tool. The following notation is used in the descriptions of the EQM steps: $x$, stands for the annual maximum precipitation, $j$ is the subscript for $5 \mathrm{~min}, 10 \mathrm{~min}, 15 \mathrm{~min}, 1 \mathrm{~h}, 2 \mathrm{~h}, 6 \mathrm{~h}, 12 \mathrm{~h}, 24 \mathrm{~h}$ sub-daily durations, $T$ the return period (in years), $o$ the observed historical series, $h$ for historical simulation period (baseline for model data), $m$ for model (downscaled GCMs), $f$ is the sub/superscript the future projected series, $p$ is the non-exceedance probability for a given $\mathrm{T}, F$ the CDF of the fitted probability GEV distribution and $F^{-1}$ the inverse CDF. The steps involved in the algorithm are as follows:

10. Extract the IDF curves, representing the historical IDF, from the gridded dataset for all durations (5 min, $10 \mathrm{~min}, 15 \mathrm{~min}, 1 \mathrm{~h}, 2 \mathrm{~h}, 6 \mathrm{~h}, 12 \mathrm{~h}, 24 \mathrm{~h}$ ) and all return periods $(2,5,10,25,50$ and 100 years) $P P T_{j, R P}$ at the selected location.

11. Extract daily maximums for the historical baseline period from the selected GCMs, $x_{m, h}$.

12. Fit the GEV probability distribution to maxima series extracted for the GCM series in (ii), $F_{m, h}$.

13. Extract daily maximums from the RCP Scenarios (i.e., RCP 2.6, RCP 4.5, RCP 8.5) for the selected GCM model, $x_{m, f}$. 
14. Fit the GEV probability distribution to the daily maximums from the GCM model for each of the future scenarios $F_{m, p}$.

15. For each projected future precipitation series, calculate the quantiles $\left(Q_{R P, m, f}\right)$ using the non-exceedance probability $\left(p_{R P}\right)$ for each $\mathrm{T}(2,5,10,25,50$ and 100 years) from the inverse CDF of the fitted GEV, $F_{m, f}^{-1}$. Similarly, calculate the quantiles $\left(\hat{Q}_{R P, m, h}\right)$ at the GCM historical baseline by entering the value of the non-exceedance probability for each $\mathrm{T}$ in the inverse CDF $F_{m, h}^{-1}$. This is a scaling step introduced to incorporate the future projections in the updated IDF and mimics the concepts of quantile delta mapping [54,56]. The relative change $\Delta_{R P, m}$ is calculated using $(25)$, for each T 2, 5, 10, 25, 50 and 100 years.

$$
\begin{aligned}
& Q_{R P, m, f}=F_{m, f}^{-1}\left(p_{R P}\right) \\
& \hat{Q}_{R P, m, h}=F_{m, h}^{-1}\left(p_{R P}\right) \\
& 07 \Delta_{R P, m}=\frac{Q_{R P, m, f}}{\hat{Q}_{R P, m, h}}
\end{aligned}
$$

16. To generate the projected future IDF curves for each duration and $\mathrm{T}$, at the selected location, use $P P T_{j, R P}$ and multiple by the relative change $\Delta_{R P, m}$ from (25).

$$
P P T_{j, R P}^{p}=\Delta_{R P, m} \cdot P P T_{j, R P}
$$

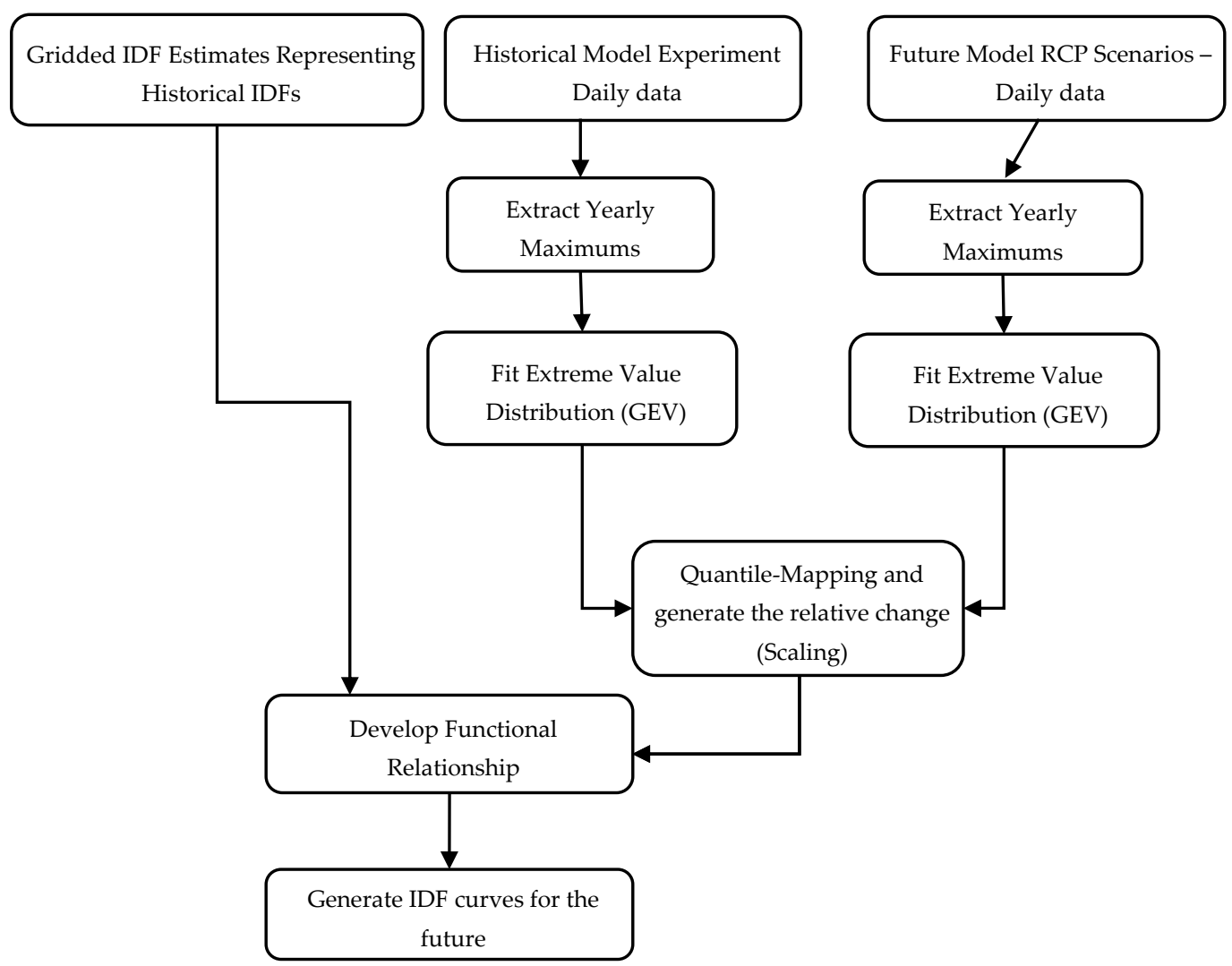

Figure 2. Modified Equidistance Quantile-Matching method for generating future IDF curves under climate change for gridded data. 


\subsection{Statistically Downscaled Global Climate Models}

The IDF_CC tool database includes 24 bias corrected and statistically downscaled GCM ([32]) projections generated using the Bias Correction Constructed Analogues with quantile (version 2) mapping reordering (BCCAQv2) method [32,55]. The models were selected based on the availability of projections (RCP 2.6, 4.5 and 8.5).

BCCAQ v2 [56] is a hybrid method that combines results from BCCA [57] and quantile mapping (QMAP) [58]. This method uses similar spatial aggregation and quantile mapping steps as Bias-Correction Spatial Disaggregation (BCSD) [59-61], but obtains spatial information from a linear combination of historical analogues for daily large-scale fields, avoiding the need for monthly aggregates [32]. QMAP applies quantile mapping to daily climate model outputs that have been interpolated to the high-resolution grid using the climate imprint method of [62].

\section{IDF_CC Tool Implementation}

The web-based tool developed for updating IDF curves has the usual components of a Decision Support System (DSS), as presented in Figure 3. The user interface relies on a GIS (geographic information system) tool that is responsible for presenting stations on the map. User information, station data, climate model data and series are stored in the tool's database system. The mathematical models and algorithms assist in the IDF fitting and updating process, as described above. The primary objective of the tool is to automate and facilitate the IDF update procedure using historical observed data collected from rainfall stations and precipitation data from climate model series as the input. The update procedure requires the historical sub-daily annual maximum of observed precipitation data to be provided by the user. In the case of Canada, a repository of stations from Environmental and Climate Change Canada (ECCC - the country's official environmental agency) is pre-loaded and available through the user interface with sub-daily historical records.

The IDF_CC tool incorporates three of the most commonly used RCPs with larger available model outputs: 2.6, 4.5 and 8.5. The numbers, $(2.6,4.5$ and 8.5$)$ represent the radiative forcing values $\mathrm{W} / \mathrm{m}^{2}$ at year 2100 , accommodating a set of anthropogenic emissions, detailed in chapter 8 of IPCC AR5 [63]. More details about the energy balance models and the temperature changes projected and the correlation to each of the RCPs can be found at [64].

Based on the precipitation series, either provided by the user or from official sources, the IDF curve is first fitted to observed historical data by using Gumbel and GEV distribution. With the IDF fitted, possible changes for the future are calculated from the selected GCM model using the EQM method. Results are presented in the form of tables and interactive graphs. As mentioned, GCM models for IPCC AR 5 [17] provide scenarios for the future (RCPs), and each RCP usually has several different runs.

For this reason, a range of possible future IDFs is generated with the application of the EQM method. Results for future IDF curves are available as median, and a range representing outputs based on each available RCP in the form of tables and interactive graphs. Output uncertainty is associated with different climate projects and runs available for each GCM and RCP.

The IDF_CC tool was designed in the form of a decision support system (DSS) to generate local IDF curve information that accounts for the impacts of climate change. The following section describes the components of the tool as implemented. For details of tool implementation and use, the user can consult the IDF_CC tool Technical and User's Manual [65,66]. 


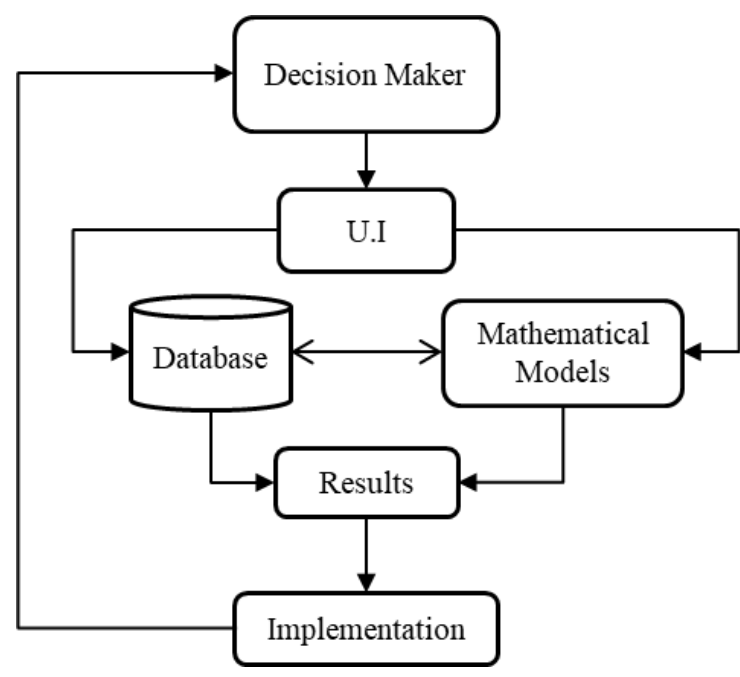

Figure 3. Decision Support System architecture of the IDF_CC tool and illustration of its support of the decision-making process.

\subsection{IDF_CC Tool Components}

This section describes the three major system components of the IDF_CC tool: (i) the user interface (UI); ii) the model base, and iii) the database and climate data models repository. The IDF_CC tool is implemented in three distinct logical layer components, as presented in Figure 4: the first layer is the user interface, the second is the model base and the third is the database and netCDF file repository.

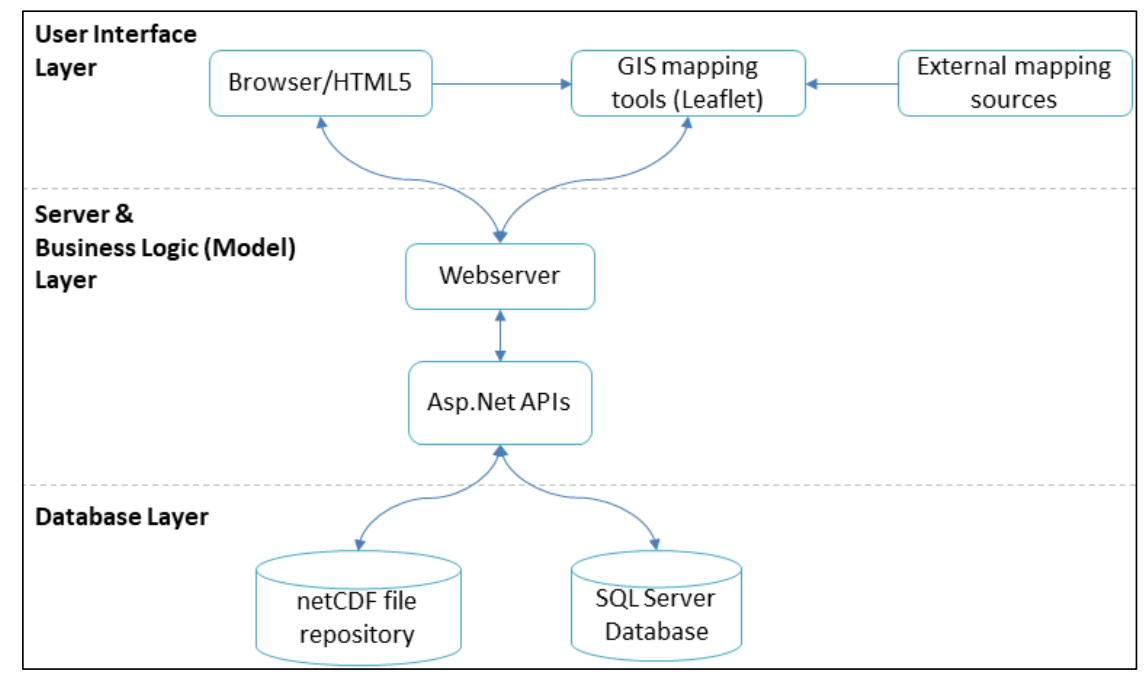

Figure 4. Elements of the layer architecture of the IDF_CC tool.

\subsection{User Interface}

The user interface provides for communication between the user and the other two DSS components: models and database. Three major parts of the user interface are: (1) Leaflet API: the GIS component responsible for map operations; (2) data manipulation: functionalities that allow users to manipulate stations and data; (3) visualization of the results: functionalities dedicated to the presentation of results to the user (tables, equations, interactive graphs). The GIS tool allows switching between several different background maps and has the common GIS functionalities such as zoom and pan (Figure 5). The data input functions are built using Excel-like spreadsheets with copy and paste functionalities. These characteristics facilitate the manipulation of the rainfall datasets that can 
be easily imported and exported from Excel spreadsheets and text files. The results are visualized through a user-friendly and interactive graphical presentation of the IDF curves and equations.

Figure 5 also presents the main menu options that allow the user to access the two main modules of the IDF_CC tool: IDFs for ungauged locations and the IDFs for gauged locations.

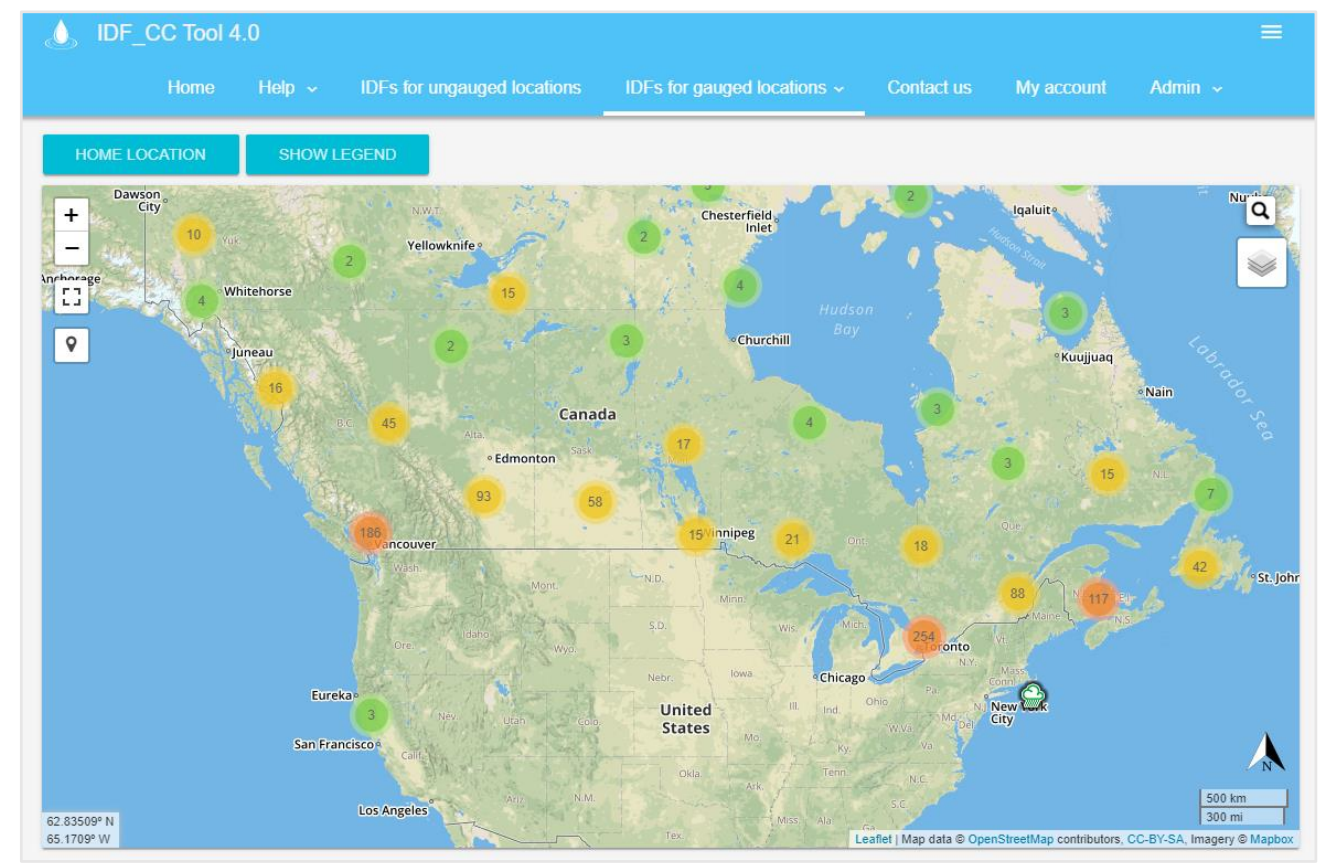

Figure 5. The IDF_CC tool user interface.

\subsection{Model Base}

The mathematical models provide support for the calculations required to develop the IDF curves based on the historical data and to incorporate climate model data to project the updated curves for the future. The list of algorithms included in the model base of the IDF_CC tool are:

- Statistical analysis algorithm is applied to fit the selected theoretical distribution to both historical (Gumbel and GEV) and future precipitation data (GEV) using the method of moments to estimate the parameters of the Gumbel distribution and L-moments method for the GEV.

- An optimization algorithm using a differential evolution (DE) optimization algorithm introduced by [67] is used on the equidistant quantile matching. The DE algorithm is used to find the coefficients of the equation to establish a statistical relationship between historical observed data and the model's baseline, as described in Section 2.4.1. The optimization algorithm is also used to fit the analytical relationships in the IDF curves. For each return period (T), an equation is fitted by finding the coefficients of the IDF equation through minimization of the sum of the root square errors between the IDF curve and equation calculated values.

- The updated equidistant quantile matching (EQM) algorithm is applied to the IDF curve updating procedure. This algorithm combines historical precipitation data with data from the climate data to develop the IDF for future periods (Section 2.4.1).

\subsection{Database}

The database stores user data, information related to stations and their data, and information from GCMs. The database management system (DBMS) used for the tool's database is the latest version of Microsoft SQL Server ${ }^{\mathrm{TM}}$ (MSSQL). Data are organized into relational tables to model aspects of reality, such as the availability of stations, their location and precipitation series, to support the calculation of IDF curves by the mathematical models. Besides tables, other essential DBMS features used by 
the tool include: (1) Views, which allow the combination of several tables in a relational way and return aggregated data to the user interface; and (2) Store procedures, which include functions that provide great flexibility for developers, and are used to insert and recover data very efficiently from the database with less computational burden. The following information is stored in the database:

- Repository of ECCC IDF curves dataset: the IDF_CC tool's database stores the latest records from the hydro-meteorological station information available from ECCC stations across the country. There are approximately 700 stations throughout the country. Only publicly available data from the ECCC stations are stored in the tool's database, including station name, location, coordinates, station ID, sub-daily AMP records and daily precipitation data.

- Dataset of gridded IDF curves for the ungauged location module. The dataset is stored in the database of the IDF_CC tool as another physical table in the database associating the coordinates with the estimates of the IDF using the methodology described in Section 2.3.

- Climate projections in the form of Global Climate Models (GCM) output files are converted from the netCDF format to an MSSQL database structure created for the IDF_CC tool that is more efficient for use with the tool's algorithms. The GCM data is available in a gridded format. For each grid point, precipitation series are available. These points cover the globe and are represented by a pair of coordinates (longitude and latitude). The database structure was created in order to allow the grid points to be stored with geographic information and the associated series in tabular form. The selection of the grid points from the GCMs and associated series is made with the use of nearest neighbor query available in MSSQL, which adds to the tool's IDF updating procedure efficiency.

- Some user information is required to access the IDF_CC tool's functionalities, and the user must create an account and provide data that are stored in the database, including their name, email, institution/municipality, the intent of use and password.

- User-provided stations and data: any registered user of IDF_CC can create stations and provide data for them. The type of data and input options are discussed in Section 4 of the paper. User-created stations can be shared among other users registered with the IDF_CC tool. Stations created by users will contain the same basic data as EC stations, including name, ID, coordinates and location. The coordinates will allow the tool to plot the station on the map with different colors for easier identification. Users are allowed to provide data for their station by including pre-processed sub-daily annual maximum precipitation (AMP) series or raw for-the-day-maximums series. The tool can identify the type of data provided and process the IDF curves calculation accordingly. There are several sub-daily durations that the user can choose from 5, 10, 15, 20 and $30 \mathrm{~min}, 1,2,3$, $6,12,18$ and $24 \mathrm{~h}$.

- Users can upload files that are related to a specific station. The files are also stored in the database and can be either text documents, spreadsheets and/or pdf files.

Data from the climate models (raw IPCC and bias corrected PCIC models) stored in the database require up to 80 gigabytes of storage space. Data from hydro-meteorological stations and miscellaneous files associated with the ECCC, which is much less demanding, take up to 700 megabytes of server space.

\subsection{IDF_CC Tool_-Technical Implementation Details}

The tool is a web-based DSS without the need for installation files and is not operating system dependent. It was built for compatibility with major web-browsers and is mobile friendly. The primary scientific and technical challenges associated with developing the IDF_CC tool are (i) to create a computationally efficient method for downscaling GCM data and updating IDF curves, and (ii) addressing complexity associated with large output files procedures by GCMs. The former was addressed by the implementation of the Equidistant Quantile Matching algorithm (EQM) $[20,65]$ and the second, by converting climate models output series from the netCDF format files into an MSSQL database integrated with the tool. The database that stores climate model data was fine-tuned to 
provide the necessary data series for the tool's mathematical models very efficiently. As a result, the updating procedures require only seconds, even when the GCM ensemble option-which includes all models-is selected.

The mathematical models and functions of the tool were written using the objected oriented C\# language, which is part of the Microsoft. Net Framework ${ }^{\mathrm{TM}}$. This programming language provides the required features to implement efficiently the optimization and the EQM algorithms and all other codes used by the tool. The user interface is based on the rich combination of technologies: Microsoft ASP.Net, HMTL5 (HyperText Markup Language version 5), CCS3 (Cascading Style Sheets, version 3), JavaScript, jQuery framework and Leaflet API for the GIS functionalities.

\section{Use of IDF_CC Tool and Results}

The IDF_CC tool provides precipitation accumulation depths for a variety of return periods $(2,5$, 10, 25, 50 and 100 years) and durations (5, 10, 15 and $30 \mathrm{~min}$ and 1, 2, 6, 12 and $24 \mathrm{~h}$ ), and allows users to generate IDF curve information based on historical data (for gauged or ungauged locations) and future climate conditions that can inform infrastructure management decisions. The users can select from multiple future greenhouse gas concentration scenarios (RCPs) and apply results from a selection of 24 raw climate models [50] and 24 bias-corrected models from PCIC [26] and the ensemble combining all models, that simulate various climate conditions at the local scale. The procedure for use of IDF_CC tool is illustrated in Figure 6.

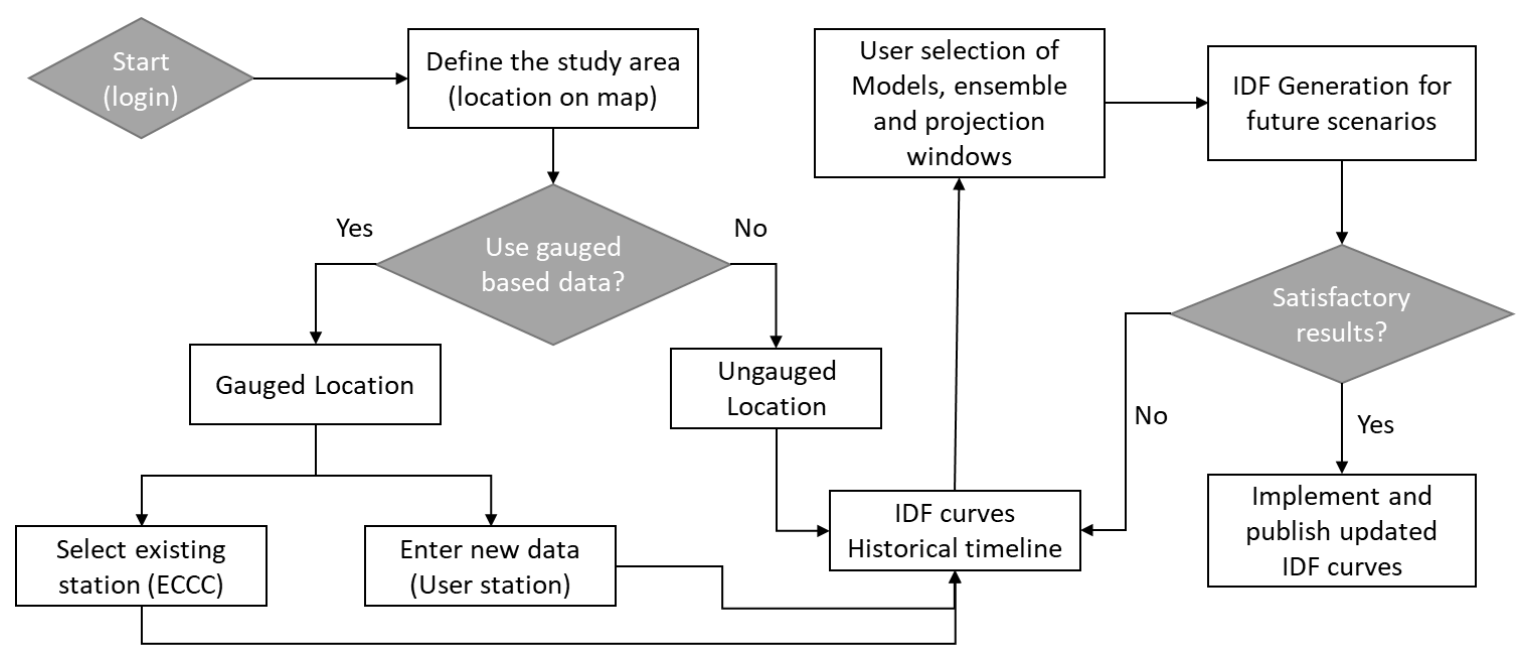

Figure 6. IDF_CC tool use flowchart.

\subsection{IDF Curves for Gauged Locations}

The tool's database stores the data for the hydro-meteorological station available from ECCC. There are approximately 700 stations publicly available for the country and roughly 500 of these have at least 10 years of observation data (the minimum length required to generate reliable IDF curves using the IDF_CC tool).

This section provides a detailed description of the main steps for IDF_CC tool use illustrated with the tool's interface screen captures. The intention here is to document the process for using the tool and assist the reader in starting to use the publicly available web-based tool.

After creating a user account and logging in, the IDF_CC tool allows users to select their location of interest by zooming in on the map, as shown in Figure 7. Alternatively, users may search for, and select, a local ECCC hydro-meteorological station using a text search box (Figure 7). Users have the option of selecting one of the 700 pre-loaded ECCC hydro-meteorological stations and creating and entering data for their own "user created" stations. 


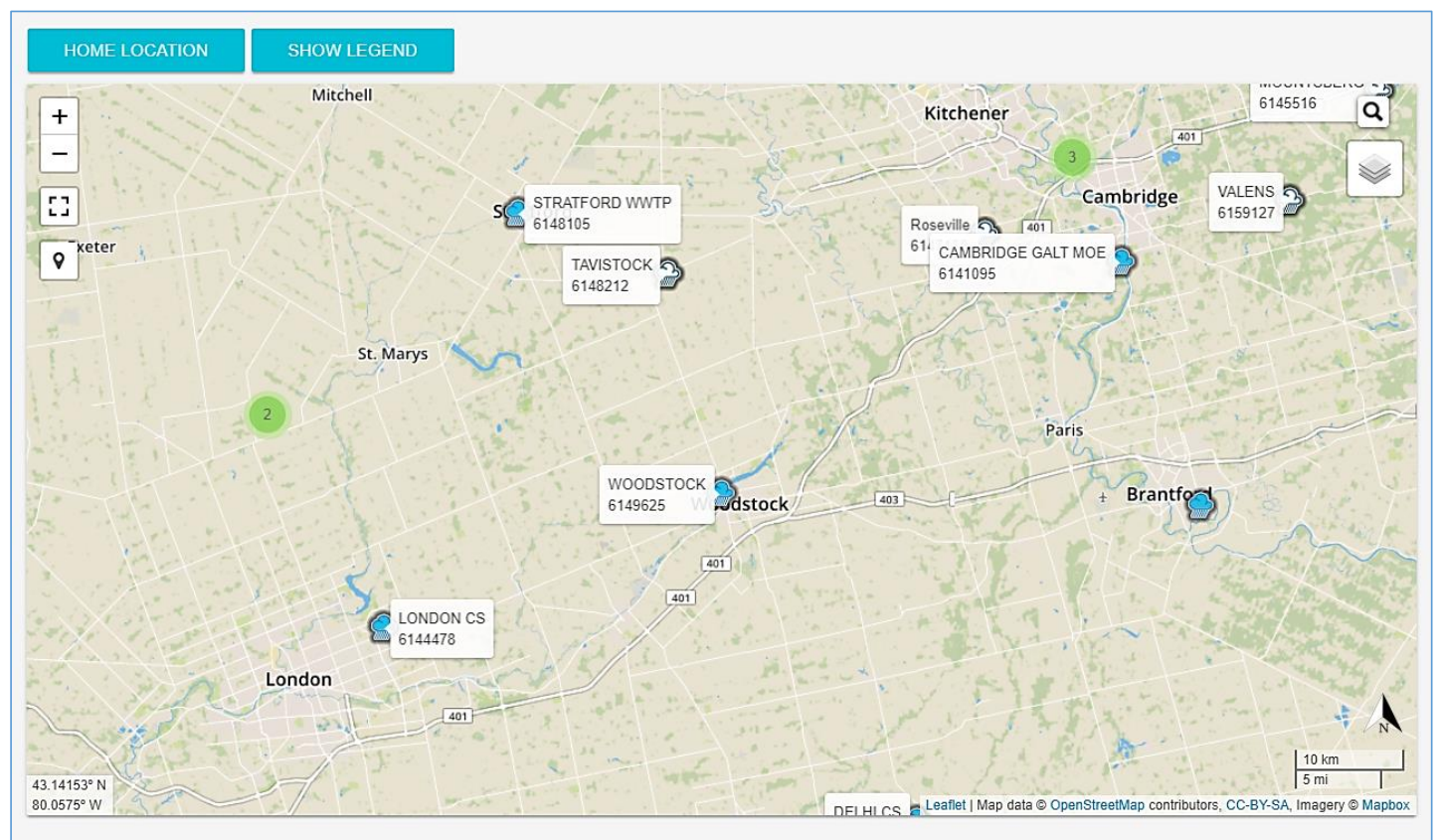

Figure 7. Stations map: Environment and Climate Change Canada (ECCC) (in blue).

Users are able to view IDF curves based on the historical records for pre-loaded and user created stations using the tool in both table (Figure 8) and plot formats (Figure 9). Users can also view interpolation equations (Figure 10) used for generating IDF curves based on historical data (from ECCC) or user entered rain station data. The return period is noted as $\mathrm{T}$ in the screenshots presented in the next figures.

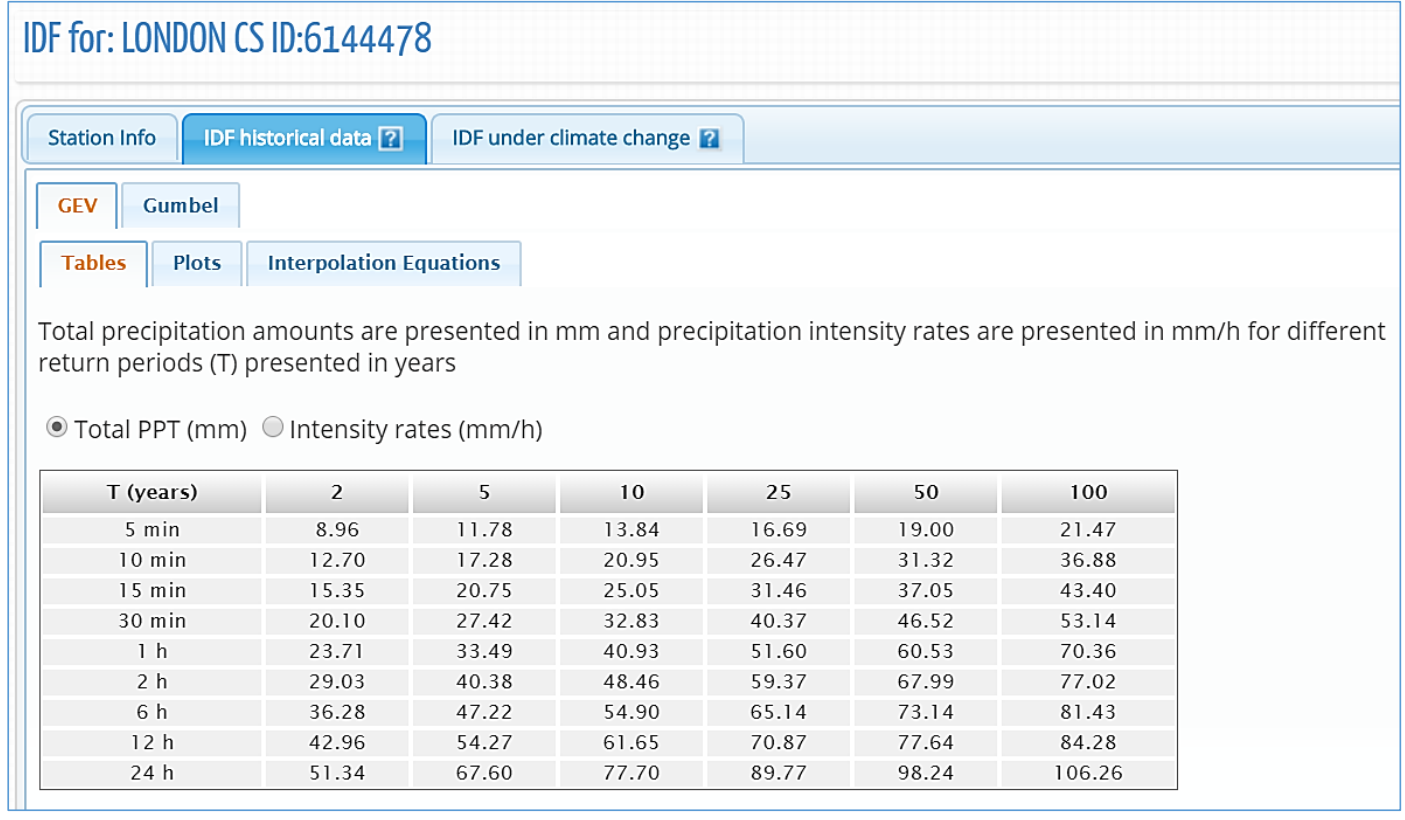

Figure 8. IDF curves for a gauged station-London CS 6144478 - total precipitation depths. 


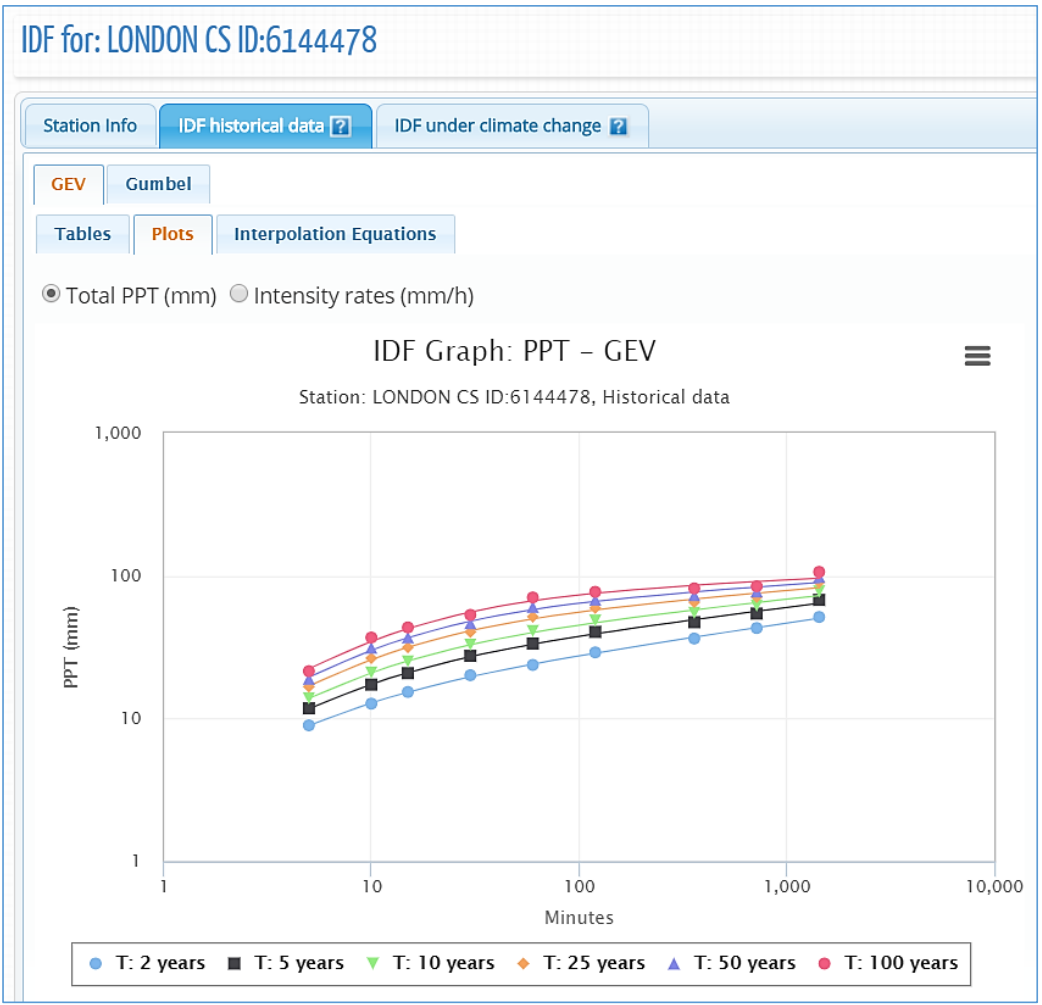

Figure 9. Total precipitation IDF depths.

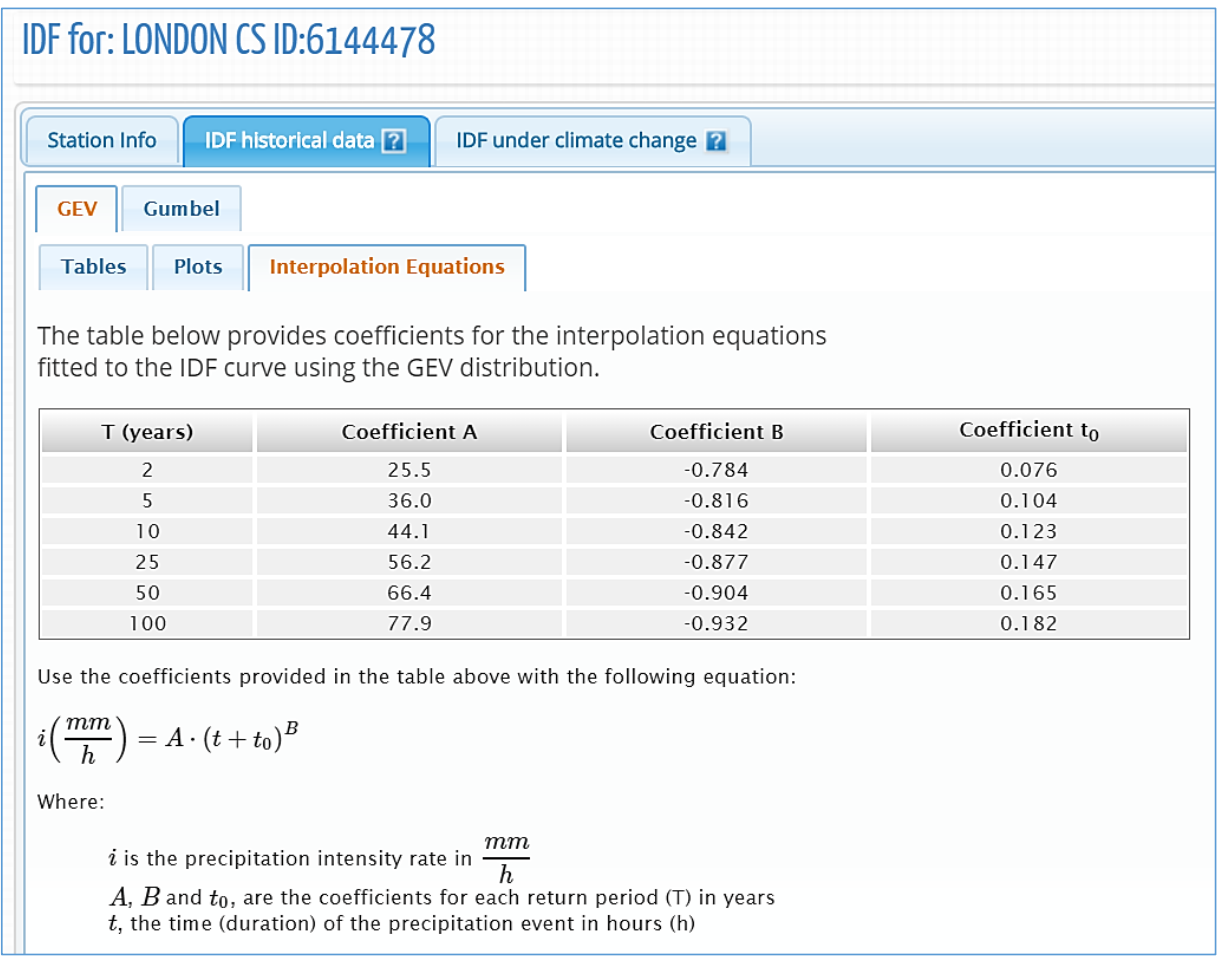

Figure 10. Fitted IDF equation.

\subsection{IDF Curves for the Ungauged Locations}

The current version of the IDF_CC tool incorporates a module with a dataset of ungauged location IDF curves covering the entire country. The input from the user for this module is the selection of a location on the map, or a pair of coordinates, as presented in Figure 11. Based on the coordinates 
selected by the user, the IDF_CC tool will extract the nearest grid points from the ungauged dataset, calculate the IDF curve for the selected location, and display the result as in Figure 12. This curve represents the historical (or observed) period. Development of updated IDFs due to climate change is presented in the next section. The locations created are saved to the user's account for later use and deleted by right clicking on the markers. The tool limits the creation of the stations within Canada only.

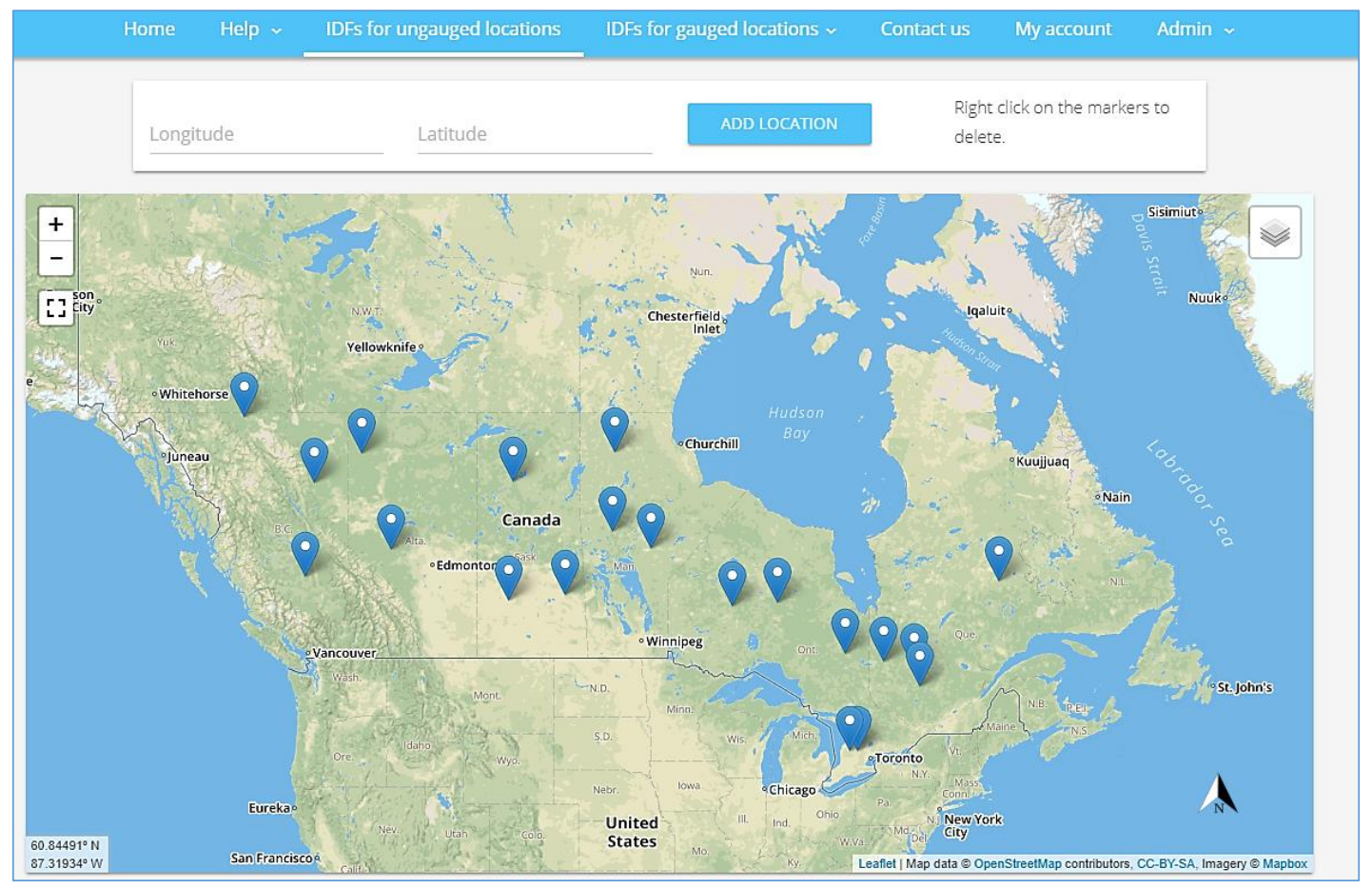

Figure 11. Various ungauged locations selected by the user.

\begin{tabular}{|c|c|c|c|c|c|c|c|}
\hline Station Info & \multicolumn{2}{|c|}{ IDF historical data [?] } & \multicolumn{3}{|c|}{ IDF under climate change } & & \\
\hline \multicolumn{8}{|l|}{ GEV } \\
\hline Tables & Plots & \multicolumn{2}{|c|}{ Interpolation Equations } & & & & \\
\hline \multirow{2}{*}{\multicolumn{8}{|c|}{$\begin{array}{l}\text { Total precipitation amounts are presented in } r \\
\text { return periods }(\mathrm{T}) \text { presented in years } \\
\text { - Total PPT }(\mathrm{mm}) \bigcirc \text { Intensity rates }(\mathrm{mm} / \mathrm{h})\end{array}$}} \\
\hline & & & & & & & \\
\hline \multicolumn{2}{|c|}{$\mathrm{T}$ (years) } & 2 & 5 & 10 & 25 & 50 & 100 \\
\hline \multicolumn{2}{|c|}{$5 \mathrm{~min}$} & 8.68 & 11.64 & 13.75 & 16.58 & 18.84 & 21.21 \\
\hline \multicolumn{2}{|c|}{$10 \mathrm{~min}$} & 12.59 & 17.05 & 20.23 & 24.61 & 28.17 & 32.02 \\
\hline \multicolumn{2}{|c|}{$15 \mathrm{~min}$} & 15.39 & 20.77 & 24.55 & 29.64 & 33.73 & 38.09 \\
\hline \multicolumn{2}{|c|}{$30 \mathrm{~min}$} & 20.18 & 27.46 & 32.59 & 39.47 & 44.91 & 50.61 \\
\hline \multicolumn{2}{|c|}{$1 \mathrm{~h}$} & 24.78 & 34.19 & 40.72 & 49.49 & 56.46 & 63.87 \\
\hline \multicolumn{2}{|c|}{$2 \mathrm{~h}$} & 29.35 & 40.86 & 49.05 & 60.27 & 69.36 & 79.15 \\
\hline \multicolumn{2}{|c|}{$6 \mathrm{~h}$} & 38.05 & 51.21 & 60.82 & 74.28 & 85.44 & 97.71 \\
\hline \multicolumn{2}{|c|}{$12 \mathrm{~h}$} & 44.10 & 58.18 & 68.22 & 82.01 & 93.25 & 105.50 \\
\hline \multicolumn{2}{|c|}{$24 \mathrm{~h}$} & 50.62 & 67.79 & 79.80 & 95.92 & 108.78 & 122.51 \\
\hline
\end{tabular}

Figure 12. IDF table for an ungagged location for a given pair of coordinates. 


\subsection{Use of IDF_CC Tool for Developing IDF Curves for Future Conditions}

The IDF_CC tool can be used to produce updated IDF curves using (i) the gauged location module with preloaded data from ECCC, or (ii) data from its own sources, or (iii) the dataset available for ungauged locations, as illustrated in Figure 6.

By selecting the "IDF under climate change" tab the users can generate IDF curves that account for future climate conditions in both modules. To generate the updated IDF curves for future climate, the user can select from 24 raw (CMIP5) and 24 bias corrected (PCIC) GCMs, all GCMs (ensemble option) or an individual model and the projection period (any minimum 30-year period between 2006 and 2100-Figure 13). The models available within the IDF_CC tool are listed in Appendix A. The minimum 50 year period was selected based on the experiments with data from the climate models and studies [68-70] that present extensive analysis of the effect of short data series on the parameters of the GEV distribution.

The steps to produce updated IDF curves can be summarized as follows: (i) select an existing or created station (gauged module) or a location on the map (ungauged module); (ii) calculate the historical IDFs that can be used for comparison with the IDFs for future climatic conditions; and (iii) select the GCM model and projection period, and generate the IDF curves for future climatic conditions. The results for each GCM model are automatically provided for three future emission scenarios (RCP2.6, RCP4.5 and RCP8.5).

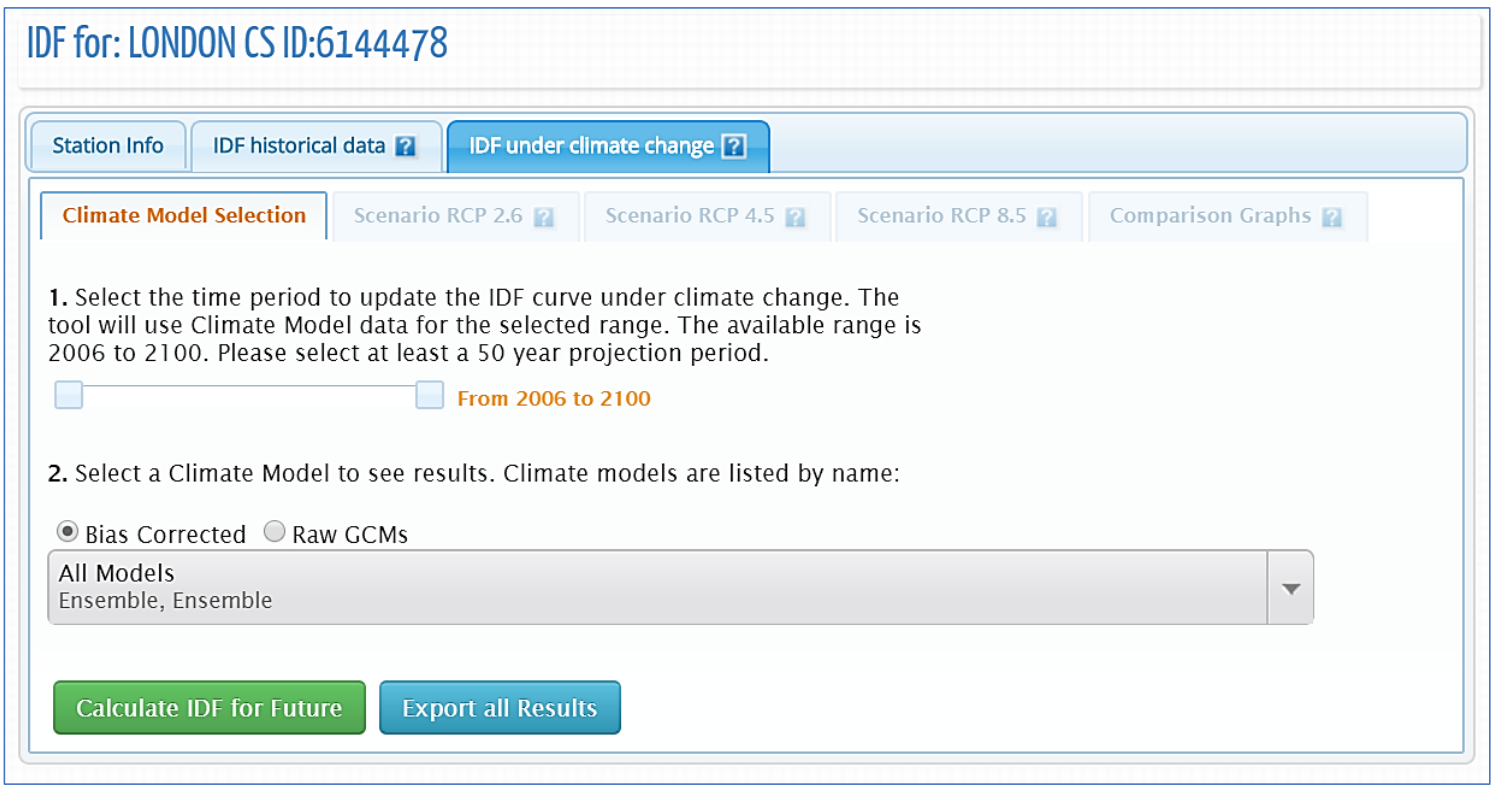

Figure 13. Screen for selection of the Global Climate Models (GCM) model and time period.

Outputs for IDF curves based on future climate scenarios are provided in tabular and graphical formats, as shown in Figures 7-9. Tables and graphs are automatically generated for each of the three available RCPs (2.6, 4.5 and 8.5). Results are provided for $5 \mathrm{~min}$ to $24 \mathrm{~h}$ durations, and for 1 in 2-to 1 in 100-year return periods (Figure 13). Further, a comparison graph can be generated to quickly assess the impact of different RCPs on outputs for a particular station (Figures 14 and 15). All the results, including plots and tables, can be exported for use outside of the tool. Users also have the option of exporting future IDF results in CSV file format for analysis. Exported future IDF results contain outputs reflecting the user's selection of the climate models and projection period. 


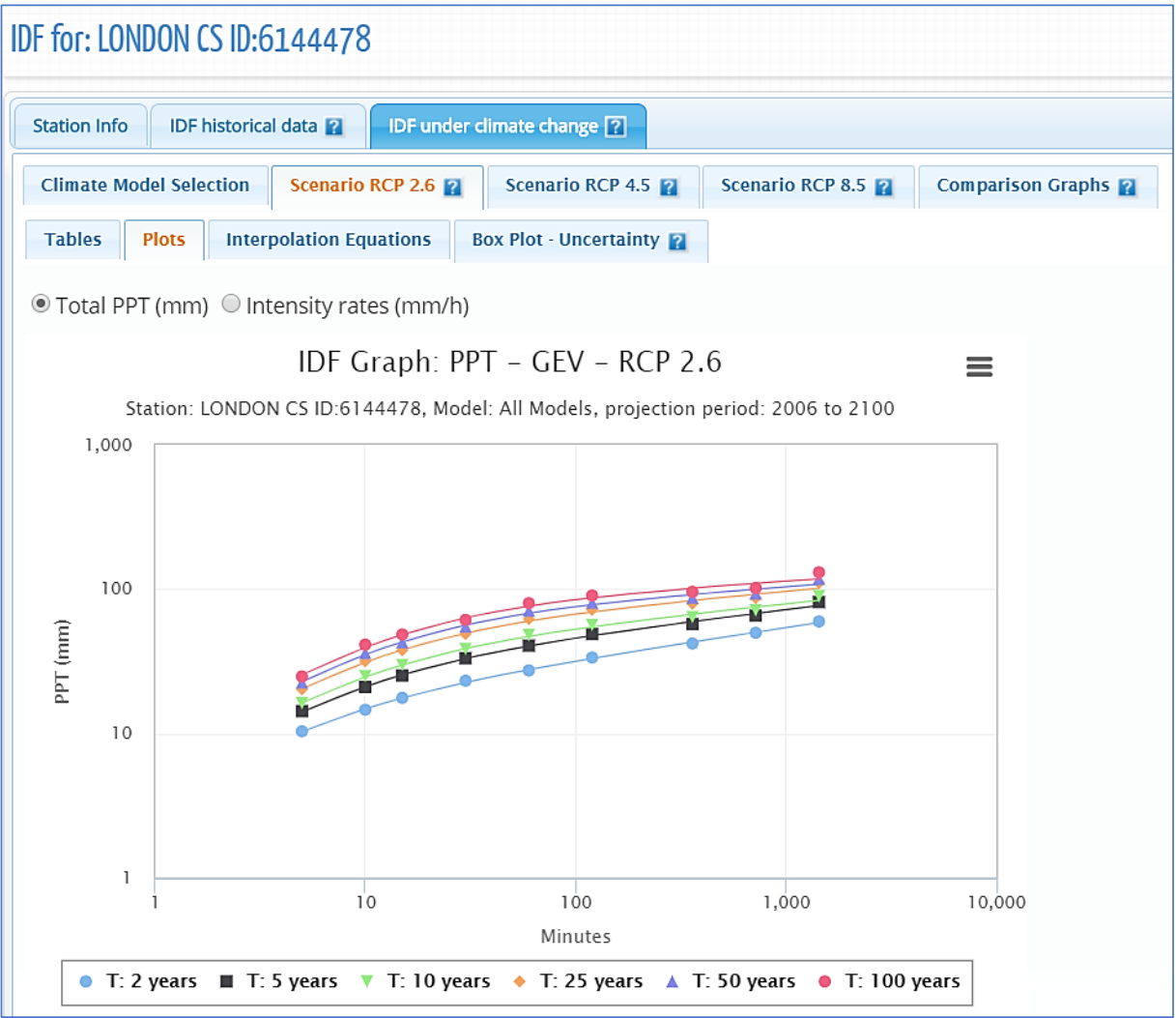

Figure 14. Updated IDF curves for Representative Concentration pathway (RCP) 2.6 and ensemble of all raw GCMs.

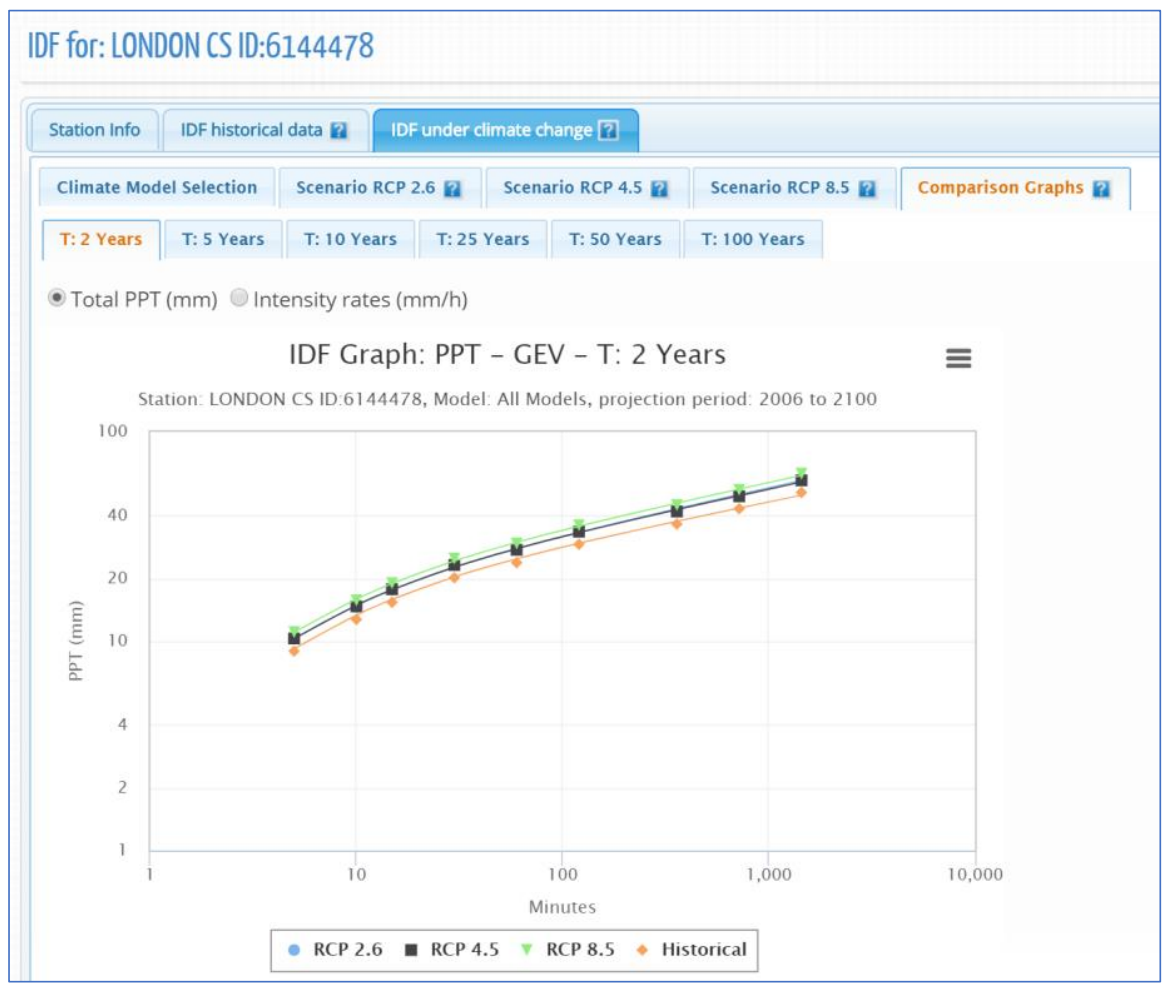

Figure 15. Comparison graph to assess the impact of different RCPs. 


\subsection{Sensitivity Analysis and Comparison of Results}

To validate the results from the presented methodology, a brief comparison between projections of the bias-corrected models and literature values from previously published material for the London CS station is conducted. The projections that the IDF_CC tool produces cannot be compared directly with other sources, given the innovative and unique nature of our work. The comparison of results also depends on the choice of selected parameters, such as the climate model, the period of analysis, and a representative pathway (RCP) selected. As an example, Table 1 presents the projected future IDF curve (the 50th of the multi-model ensemble) of the London CS station for two selected return periods of 50 and 100 years and several durations, using all 24 bias-corrected (Table A1) climate and the 24 raw (Table A2) climate models for RCP 8.5 and the late 2100 century period (2071-2100). The projections are calculated for the baseline values as presented (also indicated in Table 1). The range of projected increase in IDF values is from 25.3 to $30.1 \%$ for the 50 -year return period and 27.0 to $30.2 \%$ for the 100-year return period of the bias-corrected models, while for the raw climate models, the projected range is 25.9 to $33.9 \%$ and 25.0 to $33.5 \%$, respectively. The results show a close agreement with the dataset of climate models in the IDF_CC tool. These results (magnitude and direction of the projections) are in line with previous studies conducted for the same station $[16,23,66]$.

Table 1. Projection (\%) for London CS station, for RCP 8.5, period 2071-2100 using bias-corrected models, using the 50 th of the multi-model ensemble.

\begin{tabular}{ccccc}
\hline \multirow{2}{*}{ Duration $\backslash$ T (Years) } & \multicolumn{2}{c}{ Bias Correct Climate Models } & \multicolumn{2}{c}{ Raw Climate Models } \\
\cline { 2 - 5 } & $\mathbf{5 0}$ Years & $\mathbf{1 0 0}$ Years & $\mathbf{5 0}$ Years & $\mathbf{1 0 0}$ Years \\
\hline $5 \mathrm{~min}$ & $26.4 \%$ & $30.1 \%$ & $26.5 \%$ & $25.0 \%$ \\
\hline $10 \mathrm{~min}$ & $25.3 \%$ & $27.0 \%$ & $28.4 \%$ & $27.5 \%$ \\
\hline $15 \mathrm{~min}$ & $25.8 \%$ & $28.6 \%$ & $27.9 \%$ & $26.1 \%$ \\
\hline $30 \mathrm{~min}$ & $26.3 \%$ & $29.3 \%$ & $26.1 \%$ & $25.8 \%$ \\
\hline $1 \mathrm{~h}$ & $26.0 \%$ & $29.1 \%$ & $27.0 \%$ & $25.5 \%$ \\
\hline $2 \mathrm{~h}$ & $26.3 \%$ & $29.1 \%$ & $26.2 \%$ & $25.9 \%$ \\
\hline $6 \mathrm{~h}$ & $26.5 \%$ & $30.1 \%$ & $25.9 \%$ & $26.1 \%$ \\
\hline $12 \mathrm{~h}$ & $26.7 \%$ & $30.2 \%$ & $26.7 \%$ & $27.1 \%$ \\
\hline $24 \mathrm{~h}$ & $26.4 \%$ & $29.1 \%$ & $33.9 \%$ & $33.5 \%$ \\
\hline
\end{tabular}

The projections are compared with the MTO IDF Curves Finder tool (MTO, 2020). Once more, it is crucial to note that no direct comparison should be drawn since the methodology of the IDF_CC tool is very different from the methodology of the MTO tool. The IDF_CC tool makes use of a large number of projections (climate models). The MTO tool uses linear trend analysis to extrapolate the values from the baseline (historical period) to obtain future projects, and no direct information from the climate models is incorporated. Table 2 presents the values for 50- and 100-year return periods for several sub-daily durations for both tools. The projections from the MTO tool were taken for the year 2085 (representing roughly the late century), and the projections from the IDF_CC tool represent the 50th percentile (median) from the output from the ensemble of the two climate models available for the late century (2071-2100) [71]. The results obtained from the IDF_CC tool once more show consistency in the direction and the magnitude of the projections compared to the MTO tool. A more important analysis, however, is the discussion of uncertainty presented in the next sub-section. 
Table 2. Projection for London CS station, RCP 85-Period 2071-2100 using bias corrected models (values in $\mathrm{mm}$ ).

\begin{tabular}{|c|c|c|c|c|c|c|}
\hline \multirow{3}{*}{ Duration $\backslash T$ (Years) } & \multirow{2}{*}{\multicolumn{2}{|c|}{ MTO Tool for Year 2085}} & \multicolumn{4}{|c|}{ IDF CC Tool } \\
\hline & & & \multicolumn{2}{|c|}{ Bias Correct Models } & \multicolumn{2}{|c|}{ Raw Models } \\
\hline & 50 Years & 100 Years & 50 Years & 100 Years & 50 Years & 100 Years \\
\hline $5 \mathrm{~min}$ & 22.7 & 24.8 & 23.1 & 26.7 & 23.2 & 25.7 \\
\hline $10 \mathrm{~min}$ & 28.1 & 30.7 & 37.9 & 44.6 & 38.8 & 44.8 \\
\hline $15 \mathrm{~min}$ & 31.8 & 34.8 & 45.0 & 52.9 & 45.8 & 51.8 \\
\hline $30 \mathrm{~min}$ & 39.4 & 43.0 & 57.5 & 65.9 & 57.4 & 64.1 \\
\hline $1 \mathrm{~h}$ & 48.8 & 53.3 & 74.5 & 87.2 & 75.1 & 84.8 \\
\hline $2 \mathrm{~h}$ & 60.4 & 66.0 & 83.5 & 95.5 & 83.4 & 93.2 \\
\hline $6 \mathrm{~h}$ & 85.2 & 93.0 & 91.9 & 104.8 & 91.4 & 101.6 \\
\hline $12 \mathrm{~h}$ & 105.6 & 115.2 & 102.0 & 114.8 & 102.0 & 112.0 \\
\hline $24 \mathrm{~h}$ & 132.0 & 144.0 & 127.0 & 141.7 & 134.5 & 146.4 \\
\hline
\end{tabular}

\subsection{Discussion of Uncertainty}

One of the major challenges associated with use of the IDF_CC tool is addressing and describing uncertainty associated with climate modeling. The projections provided by different models are highly uncertain due to complex processes driving precipitation and the various ways of modeling these processes. The high number of projections is available by the IDF_CC tool, combining the two climate datasets and three future RCPs $(2.6,4.5$ and 8.5$)$ - a total of 144 projections. They create a robust set of outputs available to the users. Additionally, the IDF_CC tool's flexible architecture offers users with the opportunity to apply an ensemble of GCMs, one GCM, bias-corrected GCM outputs, and/or raw climate models. To illustrate the level of uncertainty associated with various choices, an additional feature is available within the IDF_CC tool-presentation of boxplots generated from running all available GCMs, for each emission scenario using all available model experiments (runs). Figure 16 provides an example of a box plot for the 5-year return period IDF curve for the London CS station (located in Ontario, Canada) for RCP 8.5, and all 24 raw climate models. Using the outputs from the IDF_CC tool, the uncertainty graphs can be presented in another format, as shown in Figure 17, where the shaded area presents the range of all possible IDFs for the selected climate models. It is important to highlight that all the IDF projections are equally likely, given that the climate models are built using the state-of-the-art knowledge in the field of meteorology. 


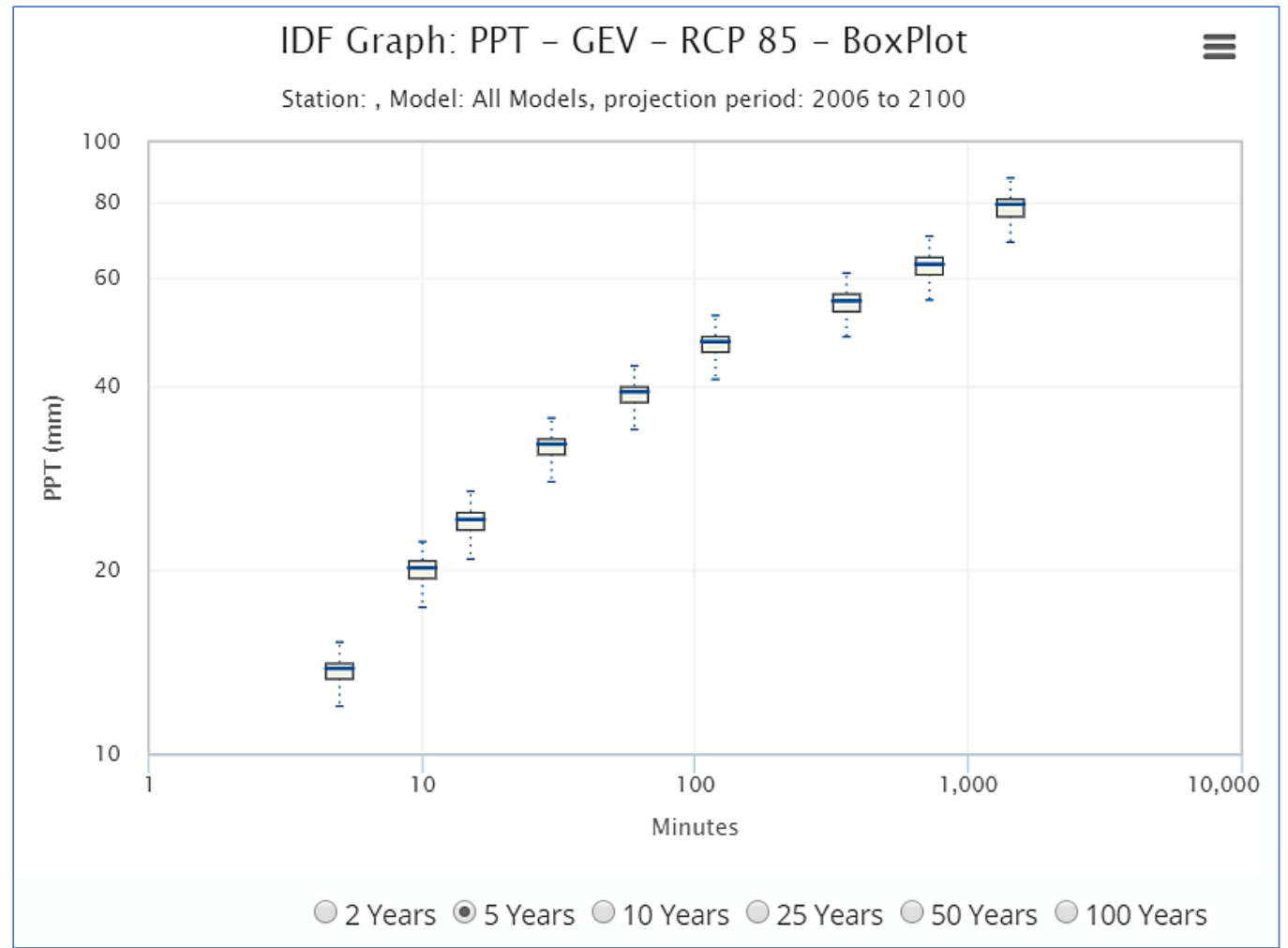

Figure 16. A Box plot of the projected range for the 5-year IDF curve for London station and RCP 8.5 using the 24 raw climate models available within the tool.

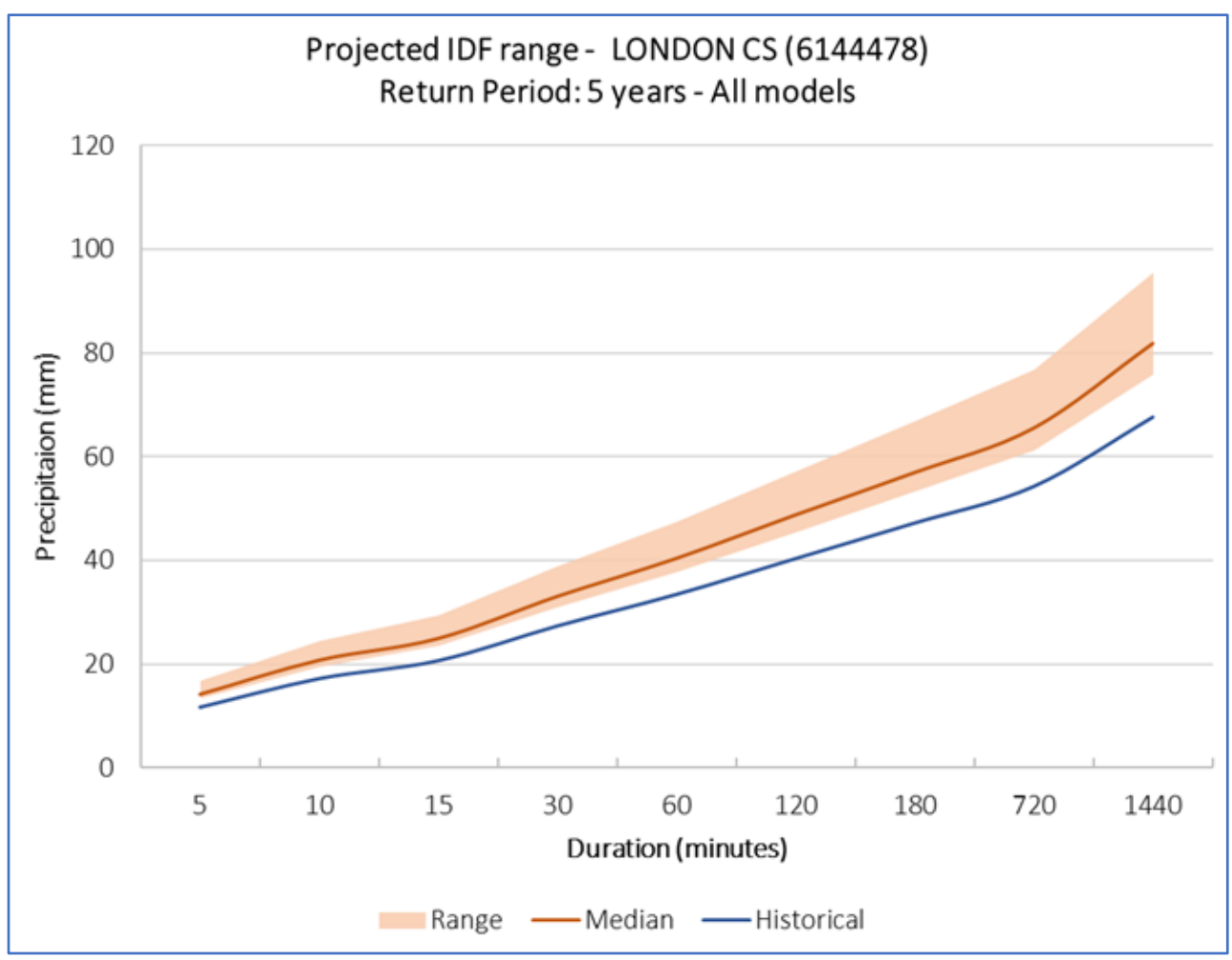

Figure 17. Projected range of the 5-year IDF curve for London station combining all models, runs and RCPs. 


\section{Conclusions}

The process of updating and incorporating climate change impacts into local IDF curves is highly technical and data-intense. The lack of relevant climate change impact information at the watershed and municipal level has been noted as a challenge that is difficult to overcome in many institutions responsible for decision making, including those with very high adaptive capacity.

Many of the current water infrastructure systems have not been designed to accommodate extreme rainfall events, and increasing urbanization is creating more impervious areas resulting in larger runoffs. Inadequate infrastructure investment and maintenance further aggravates the exposure of urban communities to flooding. Rainfall intensity-duration-frequency (IDF) curves are used for many water management applications in Canada, including planning, design, operation and maintenance of stormwater management systems, wastewater systems, stormwater detention ponds, culverts, bridges, dams, pumping stations, roads and master drainage planning.

The IDF_CC tool uses a sophisticated and efficient IDF curve updating methodology that incorporates changes in the modeled characteristics of GCMs between the baseline and the future projections. The mathematical models and procedures used within the IDF_CC tool include: (i) spatial interpolation of GCM data using the inverse distance method; (ii) statistical analyses algorithms, which include fitting Gumbel and GEV probability distribution functions using method of moments and method of L-moments, respectively; (iii) an IDF updating algorithm based on the EQM method.

The tool is designed to allow water managers, municipal infrastructure professionals, provincial and federal government agencies, researchers, consultants and non-profit groups to quickly develop estimates related to the impact of climate change on IDF curves for any location in Canada, using the gauged or un-gauged modules available within the tool.

The tool is continuously developing, and improvements are frequently being introduced. As a next step, the tool developers are planning to introduce model outputs generated by the new SSP (Shared Socio-Economical pathways) emissions scenarios, created for CMIP6, into the IDF_CC tool.

Author Contributions: A.S. was responsible for developing the methodology the user interface and components of the tool and writing the draft of the manuscript. S.P.S. was responsible for coordinating the work, design of the methodology and tool and reviewing the manuscript. A.G. was responsible for developing the methodology for the ungauged stations module and D.S. was responsible for defining the tools' functionalities, writing the manuscript and revising the final version manuscript. All authors have read and agreed to the published version of the manuscript.

Funding: The authors would like to acknowledge the financial support provided by ICLR (Institute for Catastrophic Loss Reduction) from Toronto, ON-Canada for the research and the APC.

Acknowledgments: Initial funding provided by the Canadian Water Network and continuous support of the Institute for Catastrophic Loss Reduction are greatly appreciated. The authors would like to thank the professionals who are currently using the tool, attended the workshops and participated in the webinars for their thoughtful feedback.

Conflicts of Interest: The authors declare no conflict of interest. 


\section{Appendix A. List of Bias Corrected and Raw Models}

Table A1. The selected bias corrected and downscaled CMIP5 models and their attributes which has all the three emission scenarios (RCP2.6, RCP4.5 and RCP8.5) using the BCCAQ v2 method.

\begin{tabular}{|c|c|c|c|c|c|}
\hline Country & $\begin{array}{l}\text { Centre } \\
\text { Acronym }\end{array}$ & Model & Centre Name & $\begin{array}{l}\text { Original (Longitude } \\
\text { vs. Latitude) }\end{array}$ & $\begin{array}{l}\text { Bias corrected } \\
\text { (Longitude vs. Latitude }\end{array}$ \\
\hline China & $\mathrm{BCC}$ & bcc_csm1_1 & $\begin{array}{l}\text { Beijing Climate Center, China Meteorological } \\
\text { Administration }\end{array}$ & $2.8 \times 2.8$ & \\
\hline China & $\mathrm{BCC}$ & bcc_csm1_1 m & $\begin{array}{l}\text { Beijing Climate Center, China Meteorological } \\
\text { Administration }\end{array}$ & & \\
\hline China & BNU & BNU-ESM & College of Global Change and Earth System Science & $2.8 \times 2.8$ & \\
\hline Canada & CCCma & CanESM2 & Canadian Centre for Climate Modeling and Analysis & $2.8 \times 2.8$ & \\
\hline USA & CCSM & CCSM4 & $\begin{array}{l}\text { National Center of Atmospheric Research } \\
\text { Centre National de Recherches Meteorologiques and }\end{array}$ & $1.25 \times 0.94$ & \\
\hline France & CNRM & CNRM-CM5 & $\begin{array}{l}\text { Centre Europeen de Recherches et de Formation } \\
\text { Avancee en Calcul Scientifique } \\
\text { Australian Commonwealth Scientific and Industrial }\end{array}$ & $1.4 \times 1.4$ & \\
\hline Australia & CSIRO3.6 & CSIRO-Mk3-6-0 & $\begin{array}{l}\text { Research Organization in collaboration with the } \\
\text { Queensland Climate Change Centre of Excellence }\end{array}$ & $1.8 \times 1.8$ & $0.0833 \times 0.0833$ \\
\hline USA & CESM & CESM1-CAM5 & $\begin{array}{l}\text { National Center of Atmospheric Research } \\
\text { IAP (Institute of Atmospheric Physics, Chinese }\end{array}$ & $1.25 \times 0.94$ & \\
\hline China & LASG-CESS & FGOALS_g2 & $\begin{array}{l}\text { Academy of Sciences, Beijing, China) and THU } \\
\text { (Tsinghua University) }\end{array}$ & $2.55 \times 2.48$ & \\
\hline USA & NOAA GFDL & GFDL-CM3 & $\begin{array}{l}\text { National Oceanic and Atmospheric Administration's } \\
\text { Geophysical Fluid Dynamic Laboratory }\end{array}$ & $2.5 \times 2.0$ & \\
\hline USA & NOAA GFDL & GFDL-ESM2G & $\begin{array}{l}\text { National Oceanic and Atmospheric Administration's } \\
\text { Geophysical Fluid Dynamic Laboratory }\end{array}$ & $2.5 \times 2.0$ & \\
\hline USA & NOAA GFDL & GFDL-ESM2M & $\begin{array}{l}\text { National Oceanic and Atmospheric Administration's } \\
\text { Geophysical Fluid Dynamic Laboratory }\end{array}$ & $2.5 \times 2.0$ & \\
\hline United Kingdom & MOHC & HadGEM2-AO & Met Office Hadley Centre & $1.25 \times 1.875$ & \\
\hline United Kingdom & $\mathrm{MOHC}$ & HadGEM2-ES & Met Office Hadley Centre & $1.25 \times 1.875$ & \\
\hline France & IPSL & IPSL-CM5A-LR & Institut Pierre Simon Laplace & $3.75 \times 1.8$ & \\
\hline France & IPSL & IPSL-CM5A-MR & Institut Pierre Simon Laplace & $3.75 \times 1.8$ & \\
\hline Japan & MIROC & MIROC5 & $\begin{array}{l}\text { Japan Agency for Marine-Earth Science and } \\
\text { Technology }\end{array}$ & $1.4 \times 1.41$ & \\
\hline
\end{tabular}


Table A1. Cont.

\begin{tabular}{lllll}
\hline Country & $\begin{array}{l}\text { Centre } \\
\text { Acronym }\end{array}$ & Model & Centre Name & $\begin{array}{c}\text { Original (Longitude } \\
\text { vs. Latitude) }\end{array}$ \\
\hline Japan & MIROC & MIROC-ESM & $\begin{array}{l}\text { Bias corrected } \\
\text { (Longitude vs. Latitude) }\end{array}$ & $\begin{array}{l}\text { Technology } \\
\text { Japan }\end{array}$ \\
MIROC & MIROC-ESM-CHEM & $\begin{array}{l}\text { Japan Agency for Marine-Earth Science and } \\
\text { Technology }\end{array}$ & $2.8 \times 2.8$ \\
Germany & MPI-M & MPI-ESM-LR & Max Planck Institute for Meteorology & $1.88 \times 1.87$ \\
Germany & MPI-M & MPI-ESM-MR & Max Planck Institute for Meteorology & $1.88 \times 1.87$ \\
Norway & MRI & MRI-CGCM3 & Meteorological Research Institute & $1.1 \times 1.1$ \\
Norway & NOR & NorESM1-M & Norwegian Climate Center & $2.5 \times 1.9$ \\
\hline
\end{tabular}

Table A2. The selected raw CMIP5 models and their attributes which has all the three emission scenarios (RCP2.6, RCP4.5 and RCP8.5).

\begin{tabular}{ccccc}
\hline Country & $\begin{array}{c}\text { Centre } \\
\text { Acronym }\end{array}$ & Model & Centre Name & Number of Ensembles \\
(Longitude vs. Latitude)
\end{tabular}


Table A2. Cont.

\begin{tabular}{cccccc}
\hline Country & $\begin{array}{c}\text { Centre } \\
\text { Acronym }\end{array}$ & Model & Centre Name & GCM Resolutions \\
(Longitude vs. Latitude)
\end{tabular}




\section{References}

1. CSA (Canadian Standards Association). Technical Guide: Development, Interpretation, and Use of Rainfall Intensity-Duration-Frequency (IDF) Information: Guideline for Canadian Water Resources Practitioners; Canadian Standards Association: Mississauga, ON, Canada, 2012.

2. Trenberth, K.E. Changes in precipitation with climate change. Clim. Res. 2011, 47, 1231-1238. [CrossRef]

3. Warren, F.J.; Lemmen, D.S. (Eds.) Canada in a Changing Climate: Sector Perspectives on Impacts and Adaptation; Government of Canada: Ottawa, ON, Canada, 2014; p. 286.

4. Simonovic, S.P.; Schardong, A.; Sandink, D.; Srivastav, R. A Web-based Tool for the Development of Intensity Duration Frequency Curves under Changing Climate. Environ. Model. Softw. J. 2016, 81, 136-153. [CrossRef]

5. Eum, H.I.; Simonovic, S.P. Assessment on variability of extreme climate events for the Upper Thames River basin in Canada. Hydrol. Process. 2011, 26, 485-499. [CrossRef]

6. Kao, S.C.; Ganguly, A.R. Intensity, duration, and frequency of precipitation extremes under 21st-century warming scenarios. J. Geophys. Res. 2011, 116, D16119. [CrossRef]

7. Mladjic, B.; Sushama, L.; Khaliq, M.; Laprise, R.; Caya, D.; Roy, R. Canadian RCM projected changes to extreme precipitation characteristics over Canada. J. Clim. 2011, 24, 2565-2584. [CrossRef]

8. Mailhot, A.; Kingumbi, A.; Talbot, G.; Poulin, A. Future changes in intensity and seasonal pattern of occurrence of daily and multi-day annual maximum precipitation over Canada. J. Hydrol. 2010, 388, 1731-1785. [CrossRef]

9. Katz, R.W. Statistics of extremes in climate change. Clim. Chang. 2010, 100, 71-76. [CrossRef]

10. Cunderlik, J.; Simonovic, S.P. Hydrologic extremes in South-western Ontario under future climate projections. J. Hydrol. Sci. 2005, 50, 631-654.

11. Forster, P.M.; Andrews, T.; Good, P.; Gregory, J.M.; Jackson, L.S.; Zelinka, M. Evaluating adjusted forcing and model spread for historical and future scenarios in the CMIP5 generation of climate models. J. Geophys. Res. Atmos. 2013, 118. [CrossRef]

12. Myhre, G.; Forster, P.M.; Samset, B.H.; Hodnebrog, Ø.; Sillmann, J.; Aalbergsjø, S.G.; Andrews, T.; Boucher, O.; Faluvegi, G.; Fläschner, D.; et al. PDRMIP: A Precipitation Driver and Response Model Intercomparison Project-Protocol and preliminary results. Bull. Am. Meteorol. Soc. 2017, 98, 1185-1198. [CrossRef]

13. Richardson, T.B.; Forster, P.M.; Smith, C.J.; Maycock, A.C.; Wood, T.; Andrews, T.; Boucher, O.; Faluvegi, G.; Fläschner, D.; Hodnebrog, Ø.; et al. Efficacy of Climate Forcings in PDRMIP Models. J. Geophys. Res. Atmos. 2019, 124, 12824-12844. [CrossRef] [PubMed]

14. Insurance Bureau of Canada. Facts of the Property and Casualty Insurance Industry in Canada; Insurance Bureau of Canada: Toronto, ON, Canada, 2018.

15. Sandink, D. Urban flooding and ground-related homes in Canada: An overview. J. Flood Risk Manag. 2015, 9, 208-223. [CrossRef]

16. Crabbe, P.; Robin, M. Institutional adaptation of water resource infrastructures to climate change in eastern Ontario. Clim. Chang. 2006, 78, 103-133. [CrossRef]

17. Intergovernmental Panel on Climate Change (IPCC). Contribution of Working Group I to the Fifth Assessment Report of the Intergovernmental Panel on Climate Change. Clim. Chang. 2013, 1535. [CrossRef]

18. Sugahara, S.; Rocha, R.P.; Silveira, R. Non-stationary frequency analysis of extreme daily rainfall in Sao Paulo, Brazil. Int. J. Climatol. 2009, 29, 1339-1349. [CrossRef]

19. Milly, P.C.D.; Betancourt, J.; Falkenmark, M.; Hirsch, R.M.; Kundzewicz, Z.W.; Lettenmaier, D.P.; Stouffer, R.J. Stationarity Is Dead: Whither Water Management? Science 2008, 319, 5735-5774. [CrossRef]

20. Srivastav, R.K.; Schardong, A.; Simonovic, S.P. Equidistance Quantile Matching Method for Updating IDF Curves under Climate Change. Water Resour. Manag. 2014, 28, 25392-25562. [CrossRef]

21. Cheng, L.; AghaKouchak, A. Nonstationary precipitation Intensity-Duration-Frequency curves for infrastructure design in a changing climate. Sci. Rep. 2014, 4, 7093. [CrossRef]

22. Hassanzadeh, E.; Nazemi, A.; Elshorbagy, A. Quantile-Based Downscaling of Precipitation using Genetic Programming: Application to IDF Curves in the City of Saskatoon. J. Hydrol. Eng. 2014, 19, 9439-9455. [CrossRef]

23. Peck, A.; Prodanovic, P.; Simonovic, S.P. Rainfall Intensity Duration Frequency Curves Under Climate Change: City of London, Ontario, Canada. Can. Water Resour. J. 2012, 37, 177-189. [CrossRef] 
24. Solaiman, T.A.; King, L.M.; Simonovic, S.P. Extreme precipitation vulnerability in the Upper Thames River basin: Uncertainty in climate model projections. Int. J. Climatol. 2011, 31, 2350-2364. [CrossRef]

25. Mailhot, A.; Duchesne, S.; Caya, D.; Talbot, G. Assessment of future change in intensity-duration-frequency (IDF) curves for Southern Quebec using the Canadian Regional Climate Model (CRCM). J. Hydrol. 2007, 347, 197-210. [CrossRef]

26. Sandink, D.; Simonovic, S.P.; Schardong, A.; Srivastav, R. A Decision Support System for Updating and Incorporating Climate Change Impacts into Rainfall Intensity-Duration-Frequency Curves: Review of the Stakeholder Involvement Process. Environ. Model. Softw. J. 2016, 84, 193-209. [CrossRef]

27. Chang, K.B.; Lai, S.H.; Faridah, O. RainIDF: Automated derivation of rainfall intensity-duration-frequency relationship from annual maxima and partial duration series. J. Hydroinform. 2013, 15, 1224-1233. [CrossRef]

28. Grasso., S.; Libertino, A.; Claps, P. MultiRain: A GIS-based tool for multi-model estimation of regional design rainfall for scientists and practitioners. J. Hydroinform. 2019, 16. [CrossRef]

29. Simonovic, S.P.; Schardong, A.; Sandink, D. Mapping Extreme Rainfall Statistics for Canada Under Climate Change Using Updated Intensity-Duration-Frequency Curves. ASCE J. Water Resour. Plan. Manag. 2017, 143. [CrossRef]

30. Schardong, A.; Gaur, A.; Simonovic, S.P. Comparison of the theoretical Clausius-Clapeyron scaling and IDF_CC tool for updating Intensity-Duration-Frequency Curves under climate change for Canada. J. Hydrol. Eng. 2018, 23, 04018036. [CrossRef]

31. Environmental Canada and Climate Change (ECCC). Engineering Climate Datasets. 2019. Available online: https://climate.weather.gc.ca/prods_servs/engineering_e.html (accessed on 15 September 2019).

32. Pacific Climate Impacts Consortium (PCIC). Statistically Downscaled Climate Scenarios Version 2. 2019. Available online: https://pacificclimate.org/data/statistically-downscaled-climate-scenarios (accessed on 15 September 2019).

33. Hogg, W.D.; Carr, D.A.; Routledge, B. Rainfall Intensity-Duration-Frequency Values for Canadian Locations; Environment Canada, Atmospheric Environment Service: Ottawa, ON, Canada, 1989.

34. Hosking, J.R.M.; Wallis, J.R. Regional Frequency Analysis; Cambridge University Press: Cambridge, UK, 1997.

35. Overeem, A.; Buishand, A.; Holleman, I. Rainfall depth-duration-frequency curves and their uncertainties. J. Hydrol. 2007, 348, 124-134. [CrossRef]

36. Millington, N.; Das, S.; Simonovic, S.P. The Comparison of GEV, Log-Pearson Type 3 and Gumbel Distributions in the Upper Thames River Watershed under Global Climate Models; Water Resources Research Report no. 077; Facility for Intelligent Decision Support, Department of Civil and Environmental Engineering: London, ON, Canada, 2011; p. 53, ISBN: (print) 978-0-7714-2898-2; (online) 978-0-7714-2905-7.

37. Provost, S.B.; Saboor, A.; Cordeiro, G.M.; Mansoor, M. On the q-Generalized Extreme Value Distribution REVSTAT. Stat. J. 2018, 16, 45-70.

38. Nguyen, V.T.V.; Nguye, T.D.; Cung, A. A statistical approach to downscaling of sub-daily extreme rainfall processes for climate-related impact studies in urban areas. Water Sci. Technol. Water Supply 2007, 7, 1831-1892. [CrossRef]

39. Paixao, E.; Auld, H.; Mirza, M.M.Q.; Klaassen, J.; Shephard, M.W. Regionalization of heavy rainfall to improve climatic design values for infrastructure: Case study in Southern Ontario, Canada. Hydrol. Sci. J. 2011, 56, 1067-1089. [CrossRef]

40. Coulibaly, P.; Burn, D.; Switzman, H.; Henderson, J.; Fausto, E. A comparison of future IDF curves for Southern Ontario, Technical Report, McMaster University, Hamilton. 2015. Available online: https:// climateconnections.ca/wp-content/uploads/2014/01/IDF-Comparison-Report-and-Addendum.pdf (accessed on 9 December 2018).

41. Ganguli, P.; Coulibaly, P. Does nonstationarity in rainfall require nonstationary intensity-duration-frequency curves? Hydrol. Earth Syst. Sci. 2017, 21, 6461-6483. [CrossRef]

42. Hosking, J.R.M.; Wallis, J.R.; Wood, E.F. Estimation of the Generalized Extreme-Value Distribution by the Method of Probability-Weighted Moments. Technometrics 1985, 27, 251-261. [CrossRef]

43. Hosking, J.R.M. L-Moments: Analysis and Estimation of Distributions Using Linear Combinations of Order Statistics. J. R. Stat. Soc. Ser. B 1990, 52, 105-124. [CrossRef]

44. Gaur, A.; Schardong, A.; Simonovic, S.P. Gridded extreme precipitation Intensity-Duration-Frequency estimates for the Canadian landmass. J. Hydrol. Eng. 2020, 25. [CrossRef] 
45. Mesinger, F.; DiMego, G.; Kalnay, E.; Shafran, P.C.; Ebisuzaki, W.; Jović, D.; Woollen, J.; Rogers, E.; Berbery, E.H.; Ek, M.B.; et al. North American regional reanalysis. Bull. Am. Meteorol. Soc. 2006, 87, 343-360. [CrossRef]

46. Dee, D.P.; Uppala, S.M.; Simmons, A.J.; Berrisford, P.; Poli, P.; Kobayashi, S.; Andrae, U.; Balmaseda, M.A.; Balsamo, G.; Bauer, P.; et al. The ERA-Interim reanalysis: Configuration and performance of the data assimilation system. Q. J. R. Meteorol. Soc. 2011, 137, 553-597. [CrossRef]

47. Van de Vyver, H. Spatial regression models for extreme precipitation in Belgium. Water Resour. Res. 2012, 48, W09549. [CrossRef]

48. Faulkner, D.S.; Prudhomme, C. Mapping an index of extreme rainfall across the UK. Hydrol. Earth Syst. Sci. 1998, 2, 183-194. [CrossRef]

49. Cortes, C.; Vapnik, V. Support-vector networks. Mach. Learn. 1995, 20, 273. [CrossRef]

50. Karatzoglou, A.; Smola, A.; Hornik, K. R Package Kernlab; R Foundation for Statistical Computing: Vienna, Austria, 2013.

51. Platt, J.C. Sequential Minimal Optimization: A Fast Algorithm for Training Support Vector Machines; Technical Report MSR-TR-98-14; Microsoft Research: Albuquerque, NM, USA, 1998.

52. Olsson, J.; Berggren, K.; Olofsson, M.; Viklander, M. Applying climate model precipitation scenarios for urban hydrological assessment: A case study in Kalmar City, Sweden. Atmos. Res. 2009, 92, 364-375. [CrossRef]

53. Bürger, G.; Sobie, S.R.; Cannon, A.J.; Werner, A.T.; Murdock, T.Q. Downscaling extremes-An intercomparison of multiple methods for future climate. J. Clim. 2013, 26, 34293-34449. [CrossRef]

54. Cannon, A.J.; Sobie, S.R.; Murdock, T.Q. Bias Correction of GCM Precipitation by Quantile Mapping: How Well Do Methods Preserve Changes in Quantiles and Extremes? J. Clim. 2015, 28, 69386-69959. [CrossRef]

55. Intergovernmental Panel on Climate Change (IPCC). Climate Change 2013: The Physical Science Basis. Contribution of Working Group I to the Fifth Assessment Report of the Intergovernmental Panel on Climate Change. Available online: http://www.ipcc.ch/report/ar5/wg1/ (accessed on 29 September 2019).

56. Werner, A.T.; Cannon, A.J. Hydrologic extremes-An intercomparison of multiple gridded statistical downscaling methods. Hydrol. Earth Syst. Sci. Discuss. 2015, 12, 6179-6239. [CrossRef]

57. Maurer, E.; Hidalgo, H.; Das, T.; Dettinger, M.; Cayan, D. The utility of daily large-scale climate data in the assessment of climate change impacts on daily streamflow in California (link is external). Hydrol. Earth Syst. Sci. 2010, 14, 1125-1138. [CrossRef]

58. Gudmundsson, L.; Bremnes, J.B.; Haugen, J.E.; Engen-Skaugen, T. Technical Note: Downscaling RCM precipitation to the station scale using statistical transformations-A comparison of methods (link is external). Hydrol. Earth Syst. Sci. 2012, 16, 3383-3390. [CrossRef]

59. Wood, A.W.; Leung, L.R.; Sridhar, V.; Lettenmaier, D.P. Hydrologic implications of dynamical and statistical approaches to downscaling climate model outputs. Clim. Chang. 2004, 62, 189-216. [CrossRef]

60. Maurer, E.P.; Hidalgo, H.G. Utility of daily vs. monthly large-scale climate data: An intercomparison of two statistical downscaling methods. Hydrol. Earth Syst. Sci. 2008, 12, 551-563. [CrossRef]

61. Werner, A.T. BCSD Downscaled Transient Climate Projections for Eight Select GCMs over British Columbia; Pacific Climate Impacts Consortium, University of Victoria: Victoria, BC, Canada, 2011; p. 63.

62. Hunter, R.D.; Meentemeyer, R.K. Climatologically Aided Mapping of Daily Precipitation and Temperature. J. Appl. Meteorol. 2005, 44, 1501-1510. [CrossRef]

63. Myhre, G.; Shindell, D.; Bréon, F.M.; Collins, W.; Fuglestvedt, J.; Huang, J.; Koch, D.; Lamarque, J.F.; Lee, D.; Mendoza, B.; et al. Anthropogenic and Natural Radiative Forcing. In Climate Change 2013: The Physical Science Basis. Contribution of Working Group I to the Fifth Assessment Report of the Intergovernmental Panel on Climate Change; Stocker, T.F., Qin, D., Plattner, G.-K., Tignor, M., Allen, S.K., Boschung, J., Nauels, A., Xia, Y., Bex, V., Midgley, P.M., Eds.; Cambridge University Press: Cambridge, UK; New York, NY, USA, 2013; pp. 659-740. [CrossRef]

64. Checa-Garcia, R.; Shine, K.P.; Hegglin, M.I. The Contribution of Greenhouse Gases to the Recent Slowdown in Global-Mean Temperature Trends. Environ. Res. Lett. 2016, 11, 094018. [CrossRef]

65. Schardong, A.; Gaur, A.; Simonovic, S.P.; Sandink, D. (a). Computerized Tool for the Development of IntensityDuration-Frequency Curves Under a Changing Climate: Technical Manual v.3; Water Resources Research Report no. 103; Facility for Intelligent Decision Support, Department of Civil and Environmental Engineering: London, UK; London, ON, Canada, 2018; p. 67. ISBN 978-0-7714-3107-4. 
66. Schardong, A.; Gaur, A.; Simonovic, S.P.; Sandink, D. (b). Computerized Tool for the Development of Intensity-Duration-Frequency Curves Under a Changing Climate: User's Manual v.3; Water Resources Research Report no. 104; Facility for Intelligent Decision Support, Department of Civil and Environmental Engineering: London, UK; London, ON, Canada, 2018; p. 80. ISBN 978-0-7714-3108-1.

67. Storn, R.; Price, K. Differential Evolution-A Simple and Efficient Heuristic for global Optimization over Continuous Spaces. J. Glob. Optim. 1997, 11, 341-359. [CrossRef]

68. Koutsoyiannis, D. Statistics of extremes and estimation of extreme rainfall: II. Empirical investigation of long rainfall records. Hydrol. Sci. J. 2004, 49, 610. [CrossRef]

69. Cai, X.; Hames, D. Minimum Sample Size Determination for Generalized Extreme Value Distribution. Commun. Stat. Simul. Comput. 2010, 40, 87-98. [CrossRef]

70. Ragulina, G.; Reitan, T. Generalized extreme value shape parameter and its nature for extreme precipitation using long time series and the Bayesian approach. Hydrol. Sci. J. 2017, 62, 8638-8679. [CrossRef]

71. MTO-Ontario Ministry of Transportation. MTO IDF Curves Finder Tool. 2020. Available online: http://www.mto.gov.on.ca/IDF_Curves/database_status.shtml (accessed on 10 January 2020).

(C) 2020 by the authors. Licensee MDPI, Basel, Switzerland. This article is an open access article distributed under the terms and conditions of the Creative Commons Attribution (CC BY) license (http://creativecommons.org/licenses/by/4.0/). 